APUNTE

\title{
Bosques y Biodiversidad
}

Ipinza, Roberto ${ }^{1 *}$; Barros, Santiago ${ }^{2}$, de la Maza, Carmen Luz ${ }^{3}$; Jofré, Paola ${ }^{4}$ y González, Jorge ${ }^{5}$

${ }^{1}$ Ingeniero Forestal, Universidad de Chile, Doctor Ingeniero de Montes de ETSI de Montes, Universidad Politécnica de Madrid, España. Investigador Instituto Forestal, Sede Valdivia, Chile, roberto.ipinza@infor.cl

2 Ingeniero Forestal, Universidad de Chile, Instituto Forestal, Gerencia de Investigación, Sede Metropolitana, Santiago

${ }^{3}$ Ingeniera Forestal. Universidad de Chile, Facultad de Ciencias Forestales y Conservación de la Naturaleza. Santiago.

${ }^{4}$ Ingeniera Forestal, Universidad Austral de Chile, Dra. Ciencias Forestales, Consultora, Canadá.

${ }^{5}$ Ingeniero en Biotecnología Vegetal. Investigador Instituto Forestal. Sede Bio Bio. Concepción.

${ }^{*}$ Autor para correspondencia

\section{RESUMEN}

Chile ha experimentado un cambio de la cubierta forestal desde los tiempos de la Colonia, debido a los cambios de uso de los suelos de bosques nativos a agricultura y ganadería, y a incendios forestales, miles de toneladas de suelos se han perdido por erosión como consecuencia de esto además de una importante pérdida de la diversidad biológica. Se discute y analiza el concepto de biodiversidad como una cadena que considera como base la diversidad genética, luego la diversidad de especies y por último la diversidad de ecosistemas. Chile está inmerso en una serie de tratados internacionales, no obstante, en la actualidad el mayor guardián del patrimonio de la diversidad biológica es el Ministerio de Agricultura a través Sistema Nacional de Áreas Silvestres Protegidas del Estado administrado por la Corporación Nacional Forestal (CONAF). Se analiza cuáles son las fuerzas que hacen disminuir la biodiversidad, y desde el punto de vista de esta se revisa la importancia de los bosques plantados comparando esto con el estado de erosión y degradación en que se encontraban los suelos después de ser abandonados por la agricultura y ganadería, y posteriormente ser plantados. Se pone en relieve otra fuerza, quizás la de mayor destrucción sobre la biodiversidad y sobre la vida en la tierra, "El Cambio Climático". Se analizan bajo este escenario los esfuerzos internacionales y de Chile para mitigar los impactos negativos sobre los bosques, cobijo de la biodiversidad, sumidero de carbono y almacén de agua, y cómo se puede incorporar la biodiversidad en los planes de adaptación al cambio climático. Ante la creciente y sostenida demanda mundial por productos forestales madereros se analiza cómo se armoniza el manejo forestal con la protección de la biodiversidad. En este sentido, se presta especial atención a las certificaciones internacionales de Manejo Forestal Sustentable, y a la luz de la información internacional se realizan algunas recomendaciones de futuro para incrementar la biodiversidad en bosques plantados, en especial el ordenamiento forestal del territorio productivo. La normativa internacional para proteger la biodiversidad exige un proceso de monitoreo de esta, tanto a nivel de bosques naturales como bosques plantados. Se verifica el estado actual de las iniciativas para enfrentar las amenazas a la biodiversidad, en relación al nivel de cumplimiento de los acuerdos internacionales.

Palabras clave: Biodiversidad, Diversidad genética, Bosques nativos y plantados, Cambio climático

\section{SUMMARY}

Chile has experienced a change in forest cover since colonial times, due to changes in the use of land from native forests to agriculture and livestock, and to forest fires, thousands of tons of soils have been lost due to erosion as a result of this besides in adittion to a significant loss of biological diversity. This article discusses and analyzes the concept of biodiversity as a chain that considers genetic diversity as its base, then species diversity and finally ecosystem diversity. Chile is immersed in a series of international treaties, however, at present the greatest guardian of the heritage of biological diversity is the Ministry of Agriculture through the National System of Protected Wild Areas of the State administered by the National Forestry Corporation (CONAF). The forces that make biodiversity decrease are analyzed. The importance of planted forests is analyzed from the point of view of biodiversity, comparing this with the state of erosion and degradation in which the soils are found after being abandoned by agriculture and livestock, and later being planted. Another force is brought to light, perhaps the one with the greatest destruction on biodiversity and on life on earth, "Climate Change". Under this scenario, Chile's and international efforts to mitigate negative impacts on forests, shelter for biodiversity, carbon sink and water store, and how biodiversity can be incorporated into climate change adaptation plans are analyzed under this scenario. Given the growing and sustained world demand for wood forest products, an analysis is made of how forest management is harmonized with the protection of biodiversity. Also in the light of international information, some future recommendations are made to increase biodiversity in planted forests, especially the forest management of the productive territory. International regulations to protect biodiversity require a process of monitoring it, both at the level of natural forests and planted forests. The current status of initiatives to face threats to biodiversity is verified, in relation to the level of compliance with international agreements.

Keywords: Biodiversity, Genetic diversity Native and planted forests, Climate change 


\section{INTRODUCCION}

\section{Contexto General}

La biodiversidad, según Krebs (1978) y Magurran (1989), es un término dado por la contracción de las palabras Diversidad + Biológica ${ }^{18}$, se refiere a la naturaleza con toda su complejidad, es decir, a la enorme variedad de vida sobre la Tierra fruto de miles de millones de años de procesos naturales y, cada vez más, por la influencia del ser humano.

La biodiversidad o diversidad biológica suele usarse para englobar o referirse a todos los niveles en que esa diversidad se expresa, se estructura y convive. Abarca desde la variedad y combinaciones de genes que existe en una misma población, la interacción que existe entre los individuos de esa población con su hábitat, entre estos y poblaciones de otras especies y su entorno, intercaladas con otras comunidades que tienen gradientes en las condiciones climáticas y geográficas, y que juntas conforman un ecosistema.

En específico incluye, entre otros, los organismos terrestres, marinos y de otros ecosistemas acuáticos, así como los complejos ecológicos de los que forman parte, lo que incluye diversidad dentro de las especies, entre especies y de ecosistemas.

La biodiversidad existe a diferentes niveles de organización interdependientes. En términos científicos se consideran tres niveles (Maris, 2010; Le Guyader, 2008):

- La diversidad genética (diversidad intra-específica) que se define por la variabilidad de genes en el seno de una misma especie, ya entre individuos como entre poblaciones. La diversidad genética en el seno de una misma especie es esencial para permitirle adaptarse a las modificaciones de su ambiente por las vías de la evolución.

- La diversidad específica (diversidad inter-específica), es la más conocida por su visibilidad. Corresponde a la diversidad de especies vivas, unidad de base para la sistemática, por su nombre, naturaleza y abundancia.

- La diversidad ecosistémica, que corresponde a la diversidad de los ecosistemas presentes sobre la Tierra, que forman parte de la biosfera. Este nivel de los ecosistemas se centra en la diversidad de las interacciones de las poblaciones naturales entre sí y con el medio-ambiente.

En su sentido más amplio, biodiversidad es casi sinónimo de "vida sobre la Tierra". El término biodiversidad se acuñó en 1985 y se ha utilizado mucho en los años noventa, tanto en medios de comunicación como en los círculos científicos y de las administraciones públicas.

La diversidad biológica representa un tema central de la teoría ecológica y ha sido objeto de amplio debate (Magurran, 1989).

Actualmente, el significado y la importancia de la biodiversidad no están en duda y se ha desarrollado una gran cantidad de parámetros para medirla como un indicador del estado de los sistemas ecológicos, con aplicabilidad práctica para fines de conservación, manejo y monitoreo ambiental (Spellerberg, 1991).

En un esfuerzo de contextualizar el termino biodiversidad, Rozzi, et al. (1994) establecen que para los bosques nativos de Chile la biodiversidad se caracteriza definiendo tres atributos: Composición (lista de elementos), estructura (patrón espacial) y función (procesos ecológicos y evolutivos), y cuatro niveles de organización: Genético, población-especie, comunidad-ecosistema y paisaje regional.

Lazo, et al. (2008), en una visión tradicional y más simplificada, dividen la biodiversidad en tres niveles: Genes, especies y ecosistemas, y esta se puede extender a cualquier escala o nivel de organización biológica. Estos autores muestran dicha relación en la Figura 1.

${ }^{18} \mathrm{https}: / /$ www.cepal.org/es/temas/biodiversidad 


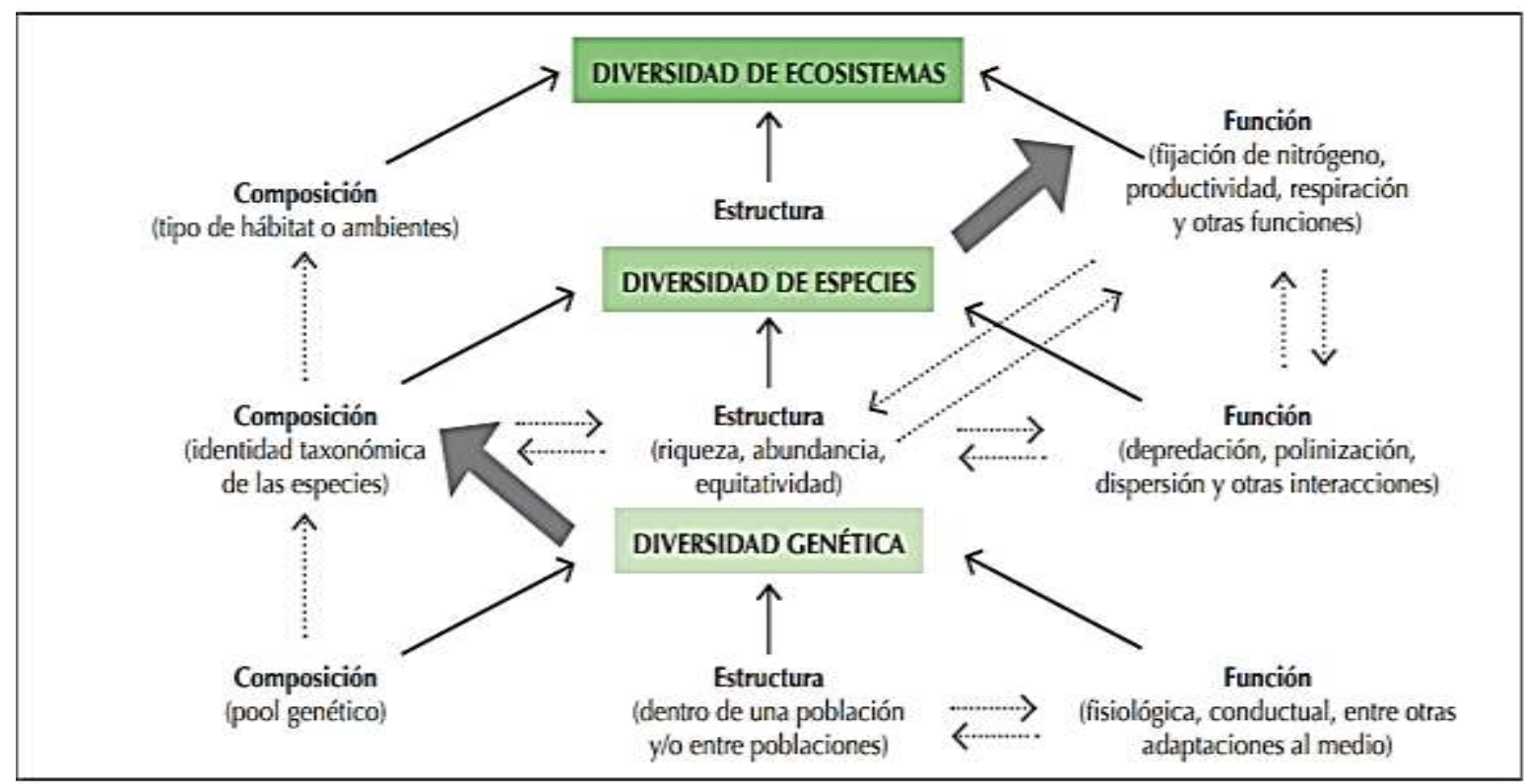

(Lazo, et al., 2008)

Figura $N^{\circ}$ 1. Representación de los Tres Niveles Clásicos de Biodiversidad y sus Relaciones Directas e Indirectas

\section{Contexto Internacional}

Existen numerosos tratados internacionales relacionados con la conservación del patrimonio natural de Chile, como la Convención para la Protección de la Flora y Fauna Washington (1940), Convenio sobre Zonas Húmedas-RAMSAR (1971), Convención sobre el Comercio Internacional de Especies Amenazadas de Fauna y Flora Silvestre-CITES (1973) y el Convenio sobre la Diversidad Biológica-CDB (1992), entre otros (BIOFIN CHILE, 2017).

De acuerdo a la actualización de la Estrategia Nacional de Biodiversidad (ENB) 2017-2030 (MMA, 2018) hay cuatro compromisos claves:

- Convenio sobre Diversidad Biológica (CDB) y Plan Estratégico para la Diversidad Biológica 2011-2020 y las Metas de Aichi.

- Objetivos de Desarrollo Sustentable, Agenda 2015 (ODS) vinculados a la ENB

- Evaluación de Desempeño Ambiental de la OCDE 2016

- Proyecto de Ley que Crea el Servicio de Biodiversidad y Áreas Protegidas (SBAP) y el Sistema Nacional de Áreas Protegidas (SNAP)

El Convenio de Naciones Unidas sobre Conservación y Uso Sostenible de la Diversidad Biológica (CDB), firmado en Río de Janeiro en junio de 1992 y ratificado por Chile en el año 1994, es el producto de un largo proceso que se inicia en octubre de 1983, donde la Asamblea General de la ONU crea la Comisión Mundial para el Medio Ambiente y el Desarrollo, del trabajo de esta comisión se elabora en 1997 el Informe Brundtland, base conceptual de la estrategia del desarrollo sostenible del CDB. Luego, en 2010, en el marco del CDB se instó a los países a actualizar sus Estrategias Nacionales de Biodiversidad (ENB) de acuerdo al Plan Estratégico para la Diversidad Biológica 2011-2020 y las Metas de Aichi. Este plan estratégico propuso 20 metas mundiales, conocidas como Metas de Aichi, orientadas a detener la pérdida de diversidad biológica a nivel global y enfrentar, a través de acciones de política pública y privada, las causas subyacentes que provocan su pérdida y deterioro. En la actualidad todas estas metas son recogidas en la Estrategia Nacional de Biodiversidad (ENB) 2017-2030 (MMA, 2018). De manera convergente, la Organización para la Cooperación y el Desarrollo Económico (OCDE) ha planteado en sus Perspectivas Ambientales al 2050 la necesidad de fortalecer las políticas públicas y los instrumentos para abordar de mejor manera las presiones directas sobre ella, a través de la promoción del uso sustentable, la inserción de los objetivos de biodiversidad en las políticas y planes intersectoriales, y la 
protección y restauración de ecosistemas y hábitats, entre otros aspectos. Por su parte, el nuevo pacto social-global que da origen a la Agenda de Desarrollo Sostenible al 2030 de Naciones Unidas, plantea 17 Objetivos de Desarrollo Sostenible (ODS), que buscan enfrentar los problemas sociales, económicos y ambientales que aquejan a los países y al planeta. De acuerdo a dicha agenda no es posible superar la pobreza, el hambre y la desigualdad si, entre otros aspectos, no se avanza seriamente en la protección y uso sostenible de la biodiversidad y los recursos naturales. En el contexto señalado, la actualización de la Estrategia Nacional de Biodiversidad es un elemento relevante para coordinar esfuerzos y procurar una retroalimentación efectiva entre objetivos globales y nacionales, en pos de la protección de la biodiversidad, la equidad y el bienestar social.

En la Estrategia Nacional de Biodiversidad (MMA, 2018) se considera que entre los principales desafíos que el país debe abordar en este ámbito se encuentra el completar y consolidar la institucionalidad ambiental vigente, a través de la creación del Servicio de Biodiversidad y Áreas Protegidas (SBAP) y del Sistema Nacional de Áreas Protegidas (SNAP), actualmente en tramitación legislativa. El Convenio sobre Diversidad Biológica (CDB) constituye el primer acuerdo mundial integral que aborda todos los aspectos de la diversidad biológica: Recursos genéticos, especies y ecosistemas, y sus objetivos son:

- La conservación de la diversidad biológica.

- El uso sostenible de los componentes de la diversidad biológica.

- El reparto justo y equitativo en los beneficios que se deriven de la utilización de los recursos genéticos.

A través del CDB se reconoce, por primera vez, que la conservación de la diversidad biológica es de interés para toda la humanidad y que esta, a su vez, es parte integrante del proceso de desarrollo comenzando una nueva forma de actuar y de entender las relaciones hombre-naturaleza. La utilización por parte del hombre de las funciones ecológicas de ciertos ecosistemas, a través de un uso reglamentado que encuadran esta utilización, adquiere la forma de un servicio para el hombre y, en la medida en que las prácticas sociales se reconozcan, el servicio también reconoce el valor de la función ecológica para el bienestar humano. Para Barbault (1997), el artículo 2 de la CDB incluye también la responsabilidad que tiene el hombre de conservar el patrimonio natural en el que está inmerso. Las medidas para evaluar y cuantificar estos servicios ecosistémicos pueden ser a menudo holísticas, difusas o relacionadas con las redes ecológicas y complejos que todavía se debaten, pero muchos experimentos o intentos de medirlos se han realizado en los últimos 20 años, sobre todo en el campo de los recursos hídricos, los bosques, el ciclo y los sumideros de carbono o del agua. Es por esto que la conservación de la diversidad biológica se ha convertido en parte fundamental de las propuestas hacia el desarrollo sustentable.

\section{Bosques en Relación a la Biodiversidad}

De acuerdo a la red de expertos del Foro Económico Mundial ${ }^{19}$ la humanidad está fuertemente ligada a los bosques. Las formas de vida de mil millones de personas dependen de las áreas forestales, que desempeñan un papel muy importante absorbiendo y almacenando el carbono, proporcionando comida, agua, productos derivados de la madera y medicinas vitales, y manteniendo gran parte de la biodiversidad del mundo, mientras que la deforestación, la degradación y la fragmentación disminuyen la capacidad de los bosques de proporcionar servicios ecosistémicos, como la purificación de aire y la regulación del clima, entre otros. Las talas ilegales o cortas sin fiscalización contribuyen a la pérdida de ingresos públicos y provocan conflictos; a fin de retener y avivar la identidad cultural y la biodiversidad, se debe cuidar y controlar de manera sostenible los bosques del mundo. Los bosques cubren casi la tercera parte de la superficie terrestre y albergan a más del $80 \%$ de la biodiversidad de esta. En los bosques tropicales se encuentra la mayor cantidad de especies por unidad de superficie terrestre, especialmente con las altas tasas de biodiversidad en la cuenca del Amazonas de América del Sur, la cuenca del Congo en África Central y la selva tropical del Sudeste Asiático. Además, los bosques con formaciones únicas, como aquellas en las islas remotas o con diversa topografía, albergan a un gran número de especies endémicas que no se encuentran en ninguna otra parte del mundo. Existe una íntima relación entre los bosques y la biodiversidad. La información detallada sobre la localización de las áreas con abundante

${ }^{19} \mathrm{https}: / /$ intelligence.weforum.org/ 
biodiversidad o bajo gran amenaza se puede utilizar para dar prioridades y hacer los mejores esfuerzos de protección y conservación.

Entre las regiones de bosques con mayor cantidad de especies por unidad de superficie terrestre y con altas tasas de biodiversidad se encuentran Brasil, África, Sudeste Asiático e Indonesia ${ }^{20}$, y para alcanzar el desarrollo sostenible resulta indispensable a futuro, especialmente en regiones como estas, la detención de la deforestación y las cortas ilícitas, la prevención y protección contra incendios forestales, el manejo forestal sostenible y en ciertos casos la protección y conservación enfocada en la mantención de la biodiversidad. Política y gobernanza adecuadas son elementos cruciales para el logro de estos objetivos dada la importancia económica, social y ambiental de estos recursos.

Es posible conservar mejor la biodiversidad minimizando la intervención humana en hábitats intactos o en aquellos relativamente poco fragmentados y restaurando las áreas con biodiversidad que hayan sufrido grandes alteraciones. Si se pueden identificar áreas como estas, el monitoreo continuo podría medir el progreso para una mejor conservación de la biodiversidad. Ya se están realizando muchos esfuerzos para proteger la biodiversidad y mitigar la destrucción de los hábitats boscosos. Los científicos han estimado que existen alrededor de 8,7 millones de especies de plantas y animales. Sin embargo, hasta ahora solo se han identificado y descrito alrededor de 1,2 millones de especies, la mayoría de las cuales son insectos. Lo anterior significa que millones de otros organismos siguen siendo un completo misterio, de la misma forma el desconocimiento de la biodiversidad que mantienen los seres vivos dentro de un hábitat edafológico común, para el caso de la agricultura, depende de su forma de uso (Swift y Anderson, 1993). Las áreas con niveles extremadamente altos de biodiversidad se denominan hotspots. Las especies endémicas, especies que solo se encuentran en un lugar en particular, también se encuentran en puntos críticos.

\section{BOSQUE Y BIODIVERSIDAD UNA RELACION ESTRECHA}

\section{Situación de los Bosques y Biodiversidad que Albergan \\ - Bosque Nativo}

La biodiversidad de los bosques naturales en Chile constituye un patrimonio natural único en el mundo, ya que acogen especies que se han desarrollado en forma aislada del resto del continente durante miles de años, debido a las barreras físicas y climáticas características del territorio chileno. El país alberga alrededor de 31.000 especies, entre plantas, animales, algas, hongos y bacterias (Universidad de Chile, 2016). En la zona centro y sur del país existe una concentración inusual de especies endémicas, por lo que esta zona fue catalogada como uno de los 35 puntos calientes o hotspots mundiales de biodiversidad (Mittermeier, et al., 2011). En relación con los ecosistemas terrestres, las formaciones de bosque nativo representan el 19,3\% de la superficie de Chile continental y son las que concentran una mayor riqueza en servicios ecosistémicos actuales y potenciales. Los bosques nativos se ubican a través de todo el país y se concentran en la zona sur, especialmente entre la regiones de Los Lagos y Magallanes que cuentan con la mayor superficie a nivel nacional de los bosques de los Tipos Forestales Siempreverde y Lenga (MMA, 2012). Cabe destacar que los recursos genéticos más valiosos son los endémicos, puesto que constituyen un patrimonio único y exclusivo en el mundo (MMA, 2014). En el país casi el $25 \%$ de las especies nativas son endémicas, destacando las plantas vasculares, entre otras especies (Universidad de Chile. 2016).

\section{- Plantaciones Forestales o Bosques Plantados}

Otro grupo importante en Chile y en el mundo lo constituyen las plantaciones productivas o industriales y protectoras, las que junto a los bosques seminaturales, que comprende la regeneración natural y la plantada, constituyeron el subgrupo denominado "bosques plantados" (FAO, 2010). FAO (2015) define a estos como "bosque compuesto predominantemente por árboles establecidos mediante plantación y/o siembra deliberada, donde se espera que los árboles plantados y/o sembrados constituyan más del 50 por ciento de las existencias en formación en la madurez". También incluye el monte bajo de árboles que originalmente se plantaron o sembraron.

${ }^{20}$ (https://intelligence.weforum.org/) 
Stephens y Wagner (2007) establecen que en un 94\% de estudios revisados existe una menor biodiversidad en los bosques plantados en comparación con otros bosques. Sin embargo, algunos estudios indican una mayor biodiversidad en bosques de plantaciones en comparación con otros usos de la tierra como la agricultura. Además, estos autores sostienen que gran parte de la literatura que se informa sobre una menor biodiversidad en las plantaciones se basa en comparaciones inapropiadas, ya que se utilizan distintos bioindicadores de diversidad biológica como por ejemplo los invertebrados $(50 \%)$, aves $(36 \%)$, mamíferos $(6 \%)$ y plantas vasculares $(6 \%)$.

Finalmente, Stephens y Wagner (2007) sugieren que "sorprendentemente" existe muy poca ciencia dura que respalde una conclusión tan categórica respecto de que los bosques plantados reducen e impactan negativamente la biodiversidad, esta debe ser reemplazada por una conclusión más condicional, ya que se puede aumentar la biodiversidad mediante un manejo forestal apropiado que incluya el uso de plantaciones.

\section{Impacto Económico, Social y Ambiental de la Destrucción del Paisaje \\ - Perspectiva Global}

Las presiones antropogénicas sobre el medio ambiente han alcanzado tal magnitud que varios límites planetarios (Figura 2), como los equilibrios químicos, físicos y biológicos que mantienen el planeta en el estado en que se lo conoce, han sido sobrepasados (Rockström, et al., 2009). De estos límites, los cambios en la concentración de gases de efecto invernadero (GEI) en la atmósfera; los ciclos de nitrógeno y fosfato, alterados mediante la agricultura intensiva; y la pérdida de biodiversidad, impulsada por cambios de uso de suelo y la producción de monocultivos, son los que ocasionan más preocupación en la comunidad científica. Los cambios en estos equilibrios tienen el potencial de retroalimentarse, multiplicando los efectos adversos (Steffen et al., 2015).

En el caso de la pérdida histórica de la biodiversidad, esta es producto de una progresiva pérdida de hábitats, por el cambio de uso de suelo; la introducción de especies invasoras; y crecientemente el cambio climático. Hasta la fecha se estima que los servicios ecosistémicos que provee la naturaleza tienen un valor neto de 125 trillones de dólares (WWF, 2018) en la economía global.

De acuerdo a Rockström, et al. (2009) la extinción de especies es un proceso natural y ocurriría sin la acción humana. Sin embargo, la pérdida de biodiversidad en el Antropoceno ${ }^{21}$ se ha acelerado enormemente. Las especies se están extinguiendo a un ritmo que no se había visto desde el último evento global de extinción masiva.

En este contexto, la biodiversidad mundial se enfrenta hoy a la mayor extinción registrada en los últimos 65 millones de años, como consecuencia de los fuertes cambios ambientales asociados al rápido crecimiento de la población humana (Maass, et al., 2019).

Alonso et al. (2019) sugieren que la preocupación por la degradación de la biodiversidad y sus efectos en la economía, se expresa en el creciente número de instrumentos internacionales y medidas a nivel nacional para la protección de hábitats y especies, tales como la Declaración de Río sobre Medio Ambiente y Desarrollo (1992)22, el Convenio sobre la Diversidad Biológica (1992) ${ }^{23}$, los Principios de Ecuador (2013) ${ }^{24}$ y los Objetivos de Desarrollo Sostenible de las Naciones Unidas (2015) ${ }^{25}$.

A pesar de dichos instrumentos, WWF (2018) indica que hay pérdidas de las poblaciones de flora y fauna en torno al $60 \%$ desde 1970 . Esta pérdida es comprobable en la disminución del tamaño de las poblaciones, alteraciones en la composición de las comunidades, pérdida de hábitats en cantidad y calidad, y pérdida de servicios ecosistémicos, entre otros aspectos.

\footnotetext{
${ }^{21}$ Los geólogos dividen el tiempo de acuerdo a los cambios que están marcado en el planeta. Los cambios ambientales globales recientes, sugieren que la tierra puede haber entrado en una nueva era geológica dominada por los humanos, el Antropóceno. El análisis de las firmas antropogénicas en el registro geológico sugiere que, de las diversas fechas propuestas, dos aparecen ajustarse a los criterios para marcar el comienzo del Antropóceno: 1610 y 1964.

22 https://mma.gob.cl/wp-content/uploads/2014/08/1_DeclaracionRio_1992.pdf

${ }^{23} \mathrm{https}: / / \mathrm{www} . \mathrm{cbd}$.int/doc/legal/cbd-es.pdf

$24 \mathrm{https}: / /$ equator-principles.com/wp-content/uploads/2018/01/equator_principles_spanish_2013.pdf

${ }^{25} \mathrm{https} / / / \mathrm{www} . u n .0 r g /$ sustainabledevelopment/es/
} 


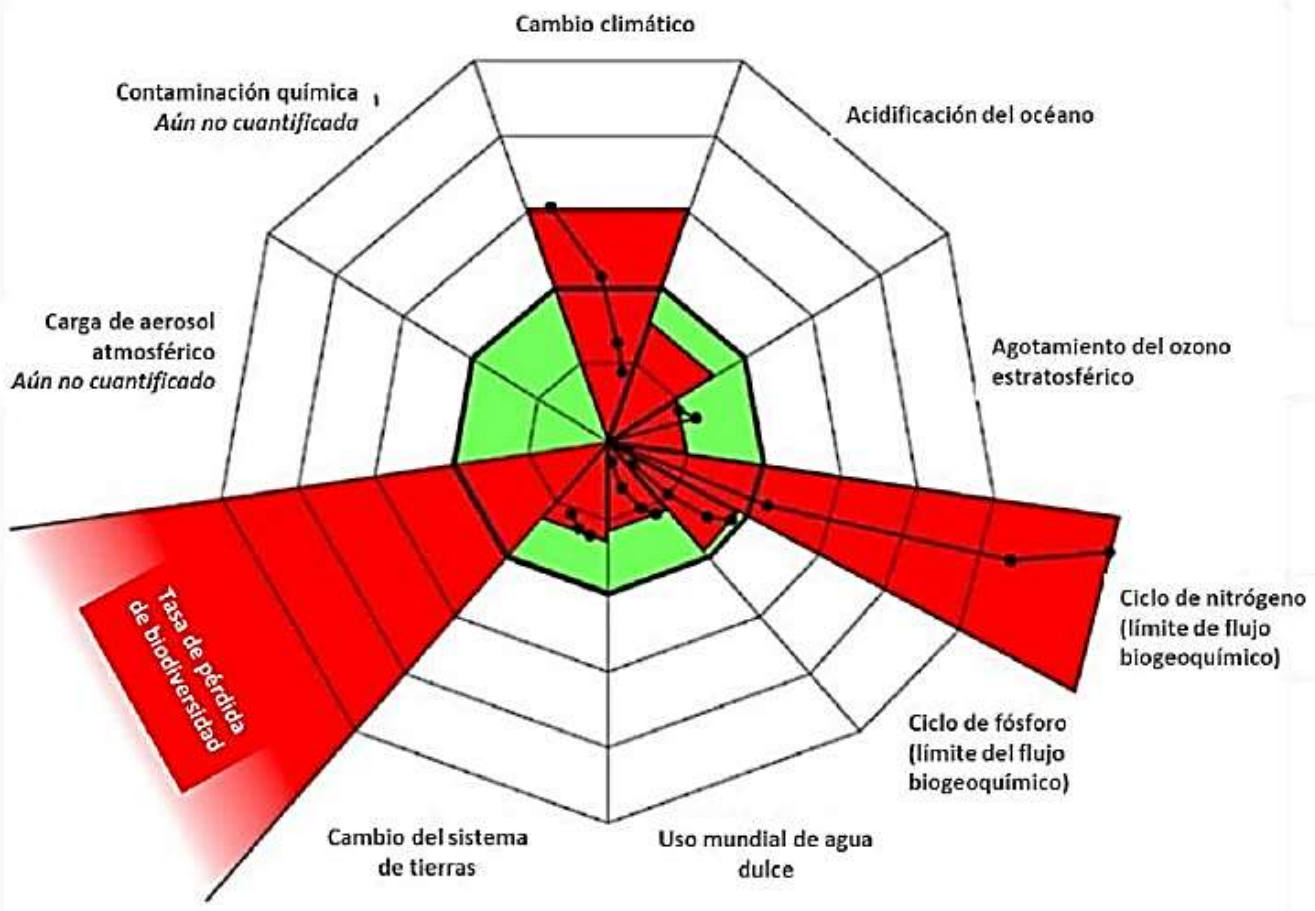

(Fuente: Modificado de Rockström et al., 2009)

El sombreado verde interior representa el espacio operativo seguro propuesto para sistemas planetarios. Las cuñas rojas representan una estimación de la posición actual de cada variable.

Los límites en los sistemas tasa de pérdida de biodiversidad, cambio climático e interferencia humana con el ciclo del nitrógeno ya han sido excedidos.

Figura 2. Más Allá del Límite de los Sistemas

La biodiversidad sobre el suelo, los vegetales y animales, ha cambiado desde que los humanos comenzaron el proceso de domesticación hace más de 7.000 años (Solbrig y Solbrig, 1994). Durante ese tiempo, los seres humanos han alterado la edafobiodiversidad, fundamentalmente a través de sus actividades agrícolas. Desde la Agricultura, este proceso implica necesariamente una reducción o simplificación de la diversidad biológica de la naturaleza, tanto a nivel de especies como genético. Las primeras actividades de los agricultores tuvieron poco impacto o estos impactos se limitaron a una escala geográfica pequeña, utilizando algunas herramientas simples e insumos, en su mayoría orgánicos. Todavía hay ejemplos de culturas que continúan practicando, a pequeña escala, esta agricultura de impacto limitado (Denevan, 1995; Redford y Mansour, 1996).

De acuerdo a la OECD (2012), a nivel global el deterioro agregado de biodiversidad y de los beneficios de los ecosistemas de bosques se estiman entre 2 y 5 billones de dólares por año. WWF (2019) estima que los bosques están siendo destruidos a un ritmo alarmante, particularmente en los trópicos. El área global de cobertura forestal es solo el $54 \%$ de lo que era en los inicios de la civilización. La pérdida de ecosistemas naturales ricos en especies está teniendo consecuencias devastadoras para los animales y los ecosistemas; donde los trópicos son el hogar de la biodiversidad más rica del planeta.

La destrucción de los bosques también está contribuyendo al cambio climático. En conjunto, la agricultura, la silvicultura y otros usos de la tierra representan alrededor del $23 \%$ de las emisiones de gases de efecto invernadero causadas por el hombre. La expansión agrícola comercial es por lejos la forma más común de cambio en la cubierta terrestre y ha cambiado la faz del planeta. En los trópicos, las tierras agrícolas aumentaron en más de 100 millones de hectáreas entre 1980 y 2000, y la mitad de este aumento fue a expensas de bosques tropicales intactos. En cambio, los bosques templados que crecen en ambos hemisferios y son particularmente productivos en el oeste de América del Norte, Chile, Nueva Zelanda y Australia, a 1990 han aumentado su superficie en aproximadamente 67 millones de hectáreas, 
en parte debido al nuevo crecimiento de la vegetación en tierras abandonadas, aunque este crecimiento secundario es relativamente pobre en biodiversidad. En un esfuerzo por abordar estos impactos a nivel global y, a la vez erradicar la pobreza, proteger el planeta y asegurar la prosperidad conjunta, Naciones Unidas adoptó en 2015 la Agenda 2030 para el Desarrollo Sostenible, que incluye 17 Objetivos de Desarrollo Sostenible (ODS). En esta Agenda al 2030, además de los objetivos que moldearán el diseño social y económico de los próximos años, también se encuentran objetivos para proteger el medio ambiente y la biodiversidad, de la cual depende una gran parte de la economía mundial.

\section{- Chile}

La pérdida y el deterioro de la biodiversidad es un proceso global, impulsado por factores directos, como el crecimiento demográfico, la eficiencia en el uso de recursos y el consumo, e indirectos, como la urbanización, el crecimiento de sectores productivos, la demanda hídrica y energética, entre otros. Esto habría significado una merma del orden del $58 \%$ en la biodiversidad planetaria (WWF, 2016) entre los años 1970 y 2012. Chile no está ajeno a esta realidad, pues ha experimentado procesos de pérdida y deterioro importantes a nivel de especies y ecosistemas, en el ámbito terrestre la mitad de los ecosistemas presentan algún grado de amenaza (Biofin Chile, 2017).

Miranda, et al. (2017), plantean que la mayor pérdida neta de bosques se observó en el período 19701990. Esta disminuyó en el período 1990-2000 y volvió a aumentar en el período 2000-2010. Este resultado revelaría una pérdida continua de bosques en los últimos 40 años. La conversión de bosque nativo en matorrales sería la contribuyente más importante a la pérdida neta de bosque nativo y representa el $45 \%$ de la pérdida. Sin embargo, no hay que olvidar que las mayores pérdidas ocurren en el siglo XVIII (1885-1960) después de la pacificación de la Araucanía, del sur de Chile, con quema de bosques para realizar agricultura y ganadería, otro período de grandes pérdidas ocurrió en los años 1930-40 con los grandes incendios en la región de Aysén, donde se quemaron 3 millones de hectáreas. No obstante, las cifras de monitoreo de CONAF indican que la tendencia en las pérdidas es a la baja, en algunos lugares se ha mantenido o sigue una tendencia a la baja o aplanamiento en la curva. La conversión a matorral nativo es producto del floreo para leña y el daño por el ganado, fundamentalmente en la pequeña propiedad, al detener estos procesos, entra a operar la restauración pasiva. Dichos autores también sugieren que en las zonas más biodiversas de bosque nativo de Chile este se transforma en plantaciones de especies exóticas. No obstante, la mayor extensión de plantaciones exóticas es en Bio Bio y Maule, en dichas zonas ya se había eliminado el bosque nativo por cultivo de trigo entre 1885 -1960. En relación al tema de la sustitución, un análisis detallado se puede revisar en Prado (2015), el que concluye que el total de superficie sustituida de bosque y matorral nativo alcanzaría a 262.967 hectáreas. Dicho autor enfatiza que una alta proporción de esta superficie corresponde a suelos que fueron deforestados para uso en agricultura y ganadería, posteriormente abandonados por estas prácticas y finalmente forestados.

Santibáñez y Royo (2002) indican que desde la zona centro norte hasta la zona sur, las principales causas atribuidas históricamente a la pérdida de ecosistemas han sido la agricultura intensiva, el uso de vegetación para leña, el sobrepastoreo, la explotación minera (aunque esta causa puede resultar irrelevantes al sur de Santiago), los incendios forestales, las plantaciones con especies exóticas y la contaminación de aguas. Muchas de estas causas han disminuido, pero otras persisten. Desde 1997 en adelante la frontera agrícola no ha crecido significativamente en Chile y la masa ganadera bovina ha disminuido en un 40\%, según los Censos Agropecuarios 1997 y $2007^{26}$ y posteriores encuestas ganaderas de INE, por lo que, en términos generales, la presión de este sector sobre la biodiversidad se debería haber estabilizado. Sin embargo, en materia de incendios forestales se ha presentado un aumento importante en cuanto a superficie afectada por año.

Pese a todas estas amenazas sobre los bosques, Chile es uno de los pocos países en el mundo que ha incrementado su cubierta forestal en las últimas décadas. Uribe y Estades (2010) sugieren que en Chile las plantaciones de pino (Pinus radiata) distribuidas principalmente entre las regiones de Maule y Bio Bio, zonas que forman parte de lo que ha sido catalogado como hotspot mundial de biodiversidad, muestran evidencias crecientes de que albergan a un número significativo de especies animales, incluyendo

${ }^{26} \mathrm{http} / / /$ bibliotecadigital.ciren.cl/handle/123456789/26503 
vertebrados e invertebrados, luego el papel de estos bosques plantados en la conservación de la biodiversidad no ha sido analizado adecuadamente.

En relación al cultivo y manejo de los bosques, tanto nativos como plantados, las empresas chilenas se han acogido a sellos de certificación forestal, ya sea bajo el Forest Stewardship Council (FSC) o el Programme for the Endorsement of Forest Certification (PEFC), ambos orientados a la gestión sustentable de los bosques y la protección de sus funciones, hábitats y biodiversidad. Estas acciones voluntarias de privados, donde existen una serie de acuerdos, códigos de buenas prácticas y certificaciones han tenido un impacto positivo sobre el uso de los recursos naturales, generando efectos significativos sobre las especies y sus hábitats. Además, la Política Nacional Forestal, impulsada por el Ministerio de Agricultura (MINAGRI) para el periodo 2015-2035, ha incorporado entre sus ejes uno denominado Protección y Restauración del Patrimonio Forestal. Este objetivo apunta a conservar e incrementar el patrimonio forestal del Estado, desarrollar los bienes y los servicios ambientales, y restaurar y proteger la biodiversidad que brindan los recursos y ecosistemas forestales. En materia de sinergias con otras convenciones internacionales, el Ministerio del Medio Ambiente (MMA) ha trabajado estrechamente en la incorporación de objetivos de biodiversidad en el Plan Nacional de Adaptación al Cambio Climático y en sus Planes Sectoriales, algunos de los cuales se encuentran ya aprobados. Entre ellos, el Plan de Adaptación al Cambio Climático en Biodiversidad, aprobado en 2014.

No obstante, se estima que, pese a los esfuerzos, las tasas de pérdida de biodiversidad no han podido ser revertidas a nivel global, principalmente porque los esfuerzos de conservación han sido enfocados a la creación de áreas protegidas y planes de recuperación de especies, entre otros, y no en enfrentar las causas que originan esta pérdida, tales como los impactos provocados por los proyectos de desarrollo productivo (MMA, 2014). Ante esto, la inclusión de la protección de la biodiversidad en los ODS, así como el creciente número de herramientas legales y técnicas que se están desarrollando, pretenden fortalecer los esfuerzos existentes para la protección de la biodiversidad y revertir esta tendencia.

\section{Percepción de la Sociedad}

Al analizar las tendencias históricas de la biología de la conservación hay que tener siempre presente que, en sus comienzos, la biología de la conservación (Campos, 2013) se orientó hacia el estudio de la naturaleza en sí misma (Nature for itself), hasta que en la década de los 80 empezó a considerarse la naturaleza a pesar de la gente (Nature despite people). A comienzos del siglo XXI, con el estudio de las funciones y servicios ecosistémicos, la biología de la conservación se enfocó en el estudio de la naturaleza para la gente (Nature for people). En los últimos años la tendencia está cambiando y la conservación se centra en el estudio de las personas y la naturaleza (People and nature) considerando los sistemas socioecológicos. En ese contexto, la UICN (2008) establece que los centros importantes para la biodiversidad suelen coincidir con zonas muy pobres. Si bien la conservación forestal podría traer buenas noticias para las comunidades locales $y$, de hecho, a menudo se promociona como beneficiosa para ellas, estas comunidades soportan costos significativos y obtienen pocos beneficios. Los costos surgen no solo de los costos de oportunidad, sino también de los intentos fallidos de planificadores y ejecutores de la conservación forestal para apoyar los derechos de las comunidades y sus miembros.

Preocupado de la percepción que tiene la sociedad chilena sobre la biodiversidad el MMA (2018) comenta la realización de dos encuestas a nivel nacional, el año 2014 y el año 2015. Se preguntó a las personas: Según su percepción y en una sola frase ¿cuál es el principal problema ambiental que le afecta a usted? Respuesta espontánea y múltiple. Como respuesta a ello, nadie mencionó algún deterioro a la biodiversidad, al patrimonio natural o a la naturaleza como un fenómeno que le afecte directamente. Pese a ello, también en ambas encuestas, el $70 \%$ de los entrevistados declara haber visitado, al menos, una vez en su vida, un Parque Nacional, Santuario Natural o Reserva Nacional. En la encuesta 2015, un 37\% señala visitar, al menos, un par de veces al año un área protegida. Ciertamente, la protección de la biodiversidad, no parece ser un tema suficientemente comprendido y del cual se sienta parte la mayoría de la población. De esto se infiere que hay un gran desafío en este tema en el país, no obstante, existen actualmente importantes esfuerzos para abordarlo. Sin embargo, no todo parece perdido ya que, en el Proceso Constituyente Abierto a la Ciudadanía en el año 2016, de un total de 90.804 personas encuestadas el $34 \%$ se manifestó a favor de incluir en la Constitución el respeto y conservación de la naturaleza como valor y principio fundamental (MMA, 2019). 
Las pérdidas de bosques naturales y seminaturales, principalmente a causa de la agricultura, debería ser una preocupación importante para la biodiversidad. En cambio sí hay mucho debate sobre las implicancias de la biodiversidad, dada la tendencia en el aumento del área de plantaciones forestales con manejo intensivo, con fines productivos y de mitigación del efecto de la erosión. En este aspecto ha surgido la percepción común que estas plantaciones son "desiertos verdes" es decir, no proporcionan un hábitat para las especies nativas (Brockerhoff et al., 2008). Qué duda cabe que los bosques naturales suelen ser más adecuados como hábitat para una gama más amplia de especies forestales nativas que los bosques plantados, pero existe abundante evidencia de que las plantaciones pueden proporcionar un hábitat valioso, incluso para algunas especies amenazadas y en peligro de extinción y pueden contribuir a la conservación de la biodiversidad por diversos mecanismos.

En paisajes donde el bosque es la cobertura natural del suelo, los bosques plantados pueden representar una matriz de bajo contraste y una forestación de tierras agrícolas puede ayudar a la conservación al proporcionar un hábitat forestal complementario, efectos de borde de impacto y una mayor conectividad (Brockerhoff et al., 2008). Por tal motivo, muchos científicos consideran que las plantaciones forestales son un "mal menor" (the lesser evil) Brockerhoff et al., 2008). Sin embargo, esta consideración es relativa al paisaje natural y a la biodiversidad de cada región, ya que por ejemplo se ha observado que en ambientes de pastizal las plantaciones forestales pueden sostener menos diversidad de especies nativas que otros usos del suelo alternativos (Filloy et al., 2010).

En el escenario actual de pérdida continua de hábitats y biodiversidad, la conservación no puede limitarse solamente al establecimiento de áreas protegidas o a la creación de regulaciones legales para el uso de los recursos naturales. Se necesita contar con el apoyo de las comunidades humanas, considerando la diversidad de percepciones, apreciaciones, valoraciones y actitudes que ellas tienen hacia la biodiversidad. En el contexto descrito, Bickford et al. (2012) plantean a nivel mundial un llamado dirigido a los biólogos de la conservación (conservacionistas, ecólogos, ingenieros forestales) a adoptar la pasión por proteger nuestros recursos naturales y ecosistemas, y dedicar más tiempo y esfuerzo a superar las barreras culturales, sociales y económicas para comunicar los mensajes ambientales, ya que son estrategias clave para el éxito. Para ayudar a la humanidad a lidiar con un mundo cambiante los científicos deben ser más provocativos, proactivos y decididos en la forma de comunicarse para crear una sociedad ambientalmente alfabetizada, que promulgue decisiones basadas tanto en ciencia sólida como en las necesidades de la humanidad. Finalmente, el MMA (2018) estima que al 2030 se habrá implementado la estrategia comunicacional y se habrá mejorado en un $50 \%$ respecto de lo observado en la línea base, tanto en lo que respecta a la percepción de la sociedad sobre el valor de la biodiversidad como en las pautas de comportamiento que posibilitan su perdurabilidad.

\section{GESTIÓN FORESTAL Y SU IMPACTO SOBRE LA BIODIVERSIDAD}

\section{El Desafío de una Creciente Demanda por Productos de los Bosques y la Mantención de Biodiversidad}

\section{- Recursos Forestales}

La Organización de las Naciones Unidas para la Alimentación y la Agricultura (FAO, 2020), en su Evaluación de los Recursos Forestales Mundiales (FRA, 2020), señala entre sus principales resultados que la cubierta forestal mundial alcanza 4.060 millones de hectáreas, lo que representa el $31 \%$ de la superficie terrestre. De esta cubierta forestal mundial, 3.750 millones de hectáreas corresponden a bosques nativos (93\%) y 290 millones de hectáreas a bosques plantados (7\%), superficie esta última constituida por 135 millones de hectáreas de plantaciones productivas bajo silvicultura intensiva y 159 millones de hectáreas de otra plantaciones forestales, que aunque pueden cumplir funciones productivas su fin principal es la protección de suelos y aguas, la retención de carbono y la protección de la biodiversidad (FAO, 2020).

Los bosques del mundo se concentran en las zonas tropicales y sub tropicales (56\%), y el resto en las zonas boreales (27\%) y templadas (16\%). A nivel de países, Rusia, Brasil, Canadá, Estados Unidos y China reúnen el $54 \%$ de la cubierta forestal total (FAO, 2020). Unos 726 millones de hectáreas (18\%) de bosques están dentro de áreas protegidas en diferentes lugares del mundo, principalmente en América del Sur, con un $31 \%$ de sus bosques bajo esta forma de protección y conservación (FAO, 2020). De la 
superficie de plantaciones forestales en el mundo, 44\% están constituidas principalmente por especies introducidas y $56 \%$ principalmente por especies nativas. En América del Norte y Central más del $95 \%$ de las plantaciones son de especies nativas y en Asia casi el 70\%, en tanto que en América del Sur la casi totalidad de las plantaciones son de especies introducidas (FAO, 2020).

En el caso de Chile, su cubierta forestal es de 17 millones de hectáreas, lo que representa aproximadamente el $20 \%$ de la superficie territorial del país, y está compuesta por 14,6 millones de hectáreas de bosques nativos, clasificados en 12 Tipos Forestales según las especies dominantes que los componen, y 2,3 millones de hectáreas de plantaciones forestales de diferentes especies, las principales de las cuales son Pinus radiata (De Don.) (56\%), Eucalyptus globulus (Labill.) (25\%), Eucalyptus nitens (Deane \& Maiden) (12\%) y una participación menor $(7 \%)$ de otras especies, de los géneros Acacia, Atriplex, Eucalyptus, Larix, Pinus, Populus, Pseudotsuga y otros (INFOR, 2020). Chile mantiene actualmente 18,6 millones de hectáreas de áreas protegidas por el Estado, en las diferentes regiones del país, que incluyen 3,8 millones de hectáreas de bosques nativos bajo régimen de protección y conservación. En tanto que la utilización de bosques nativos fuera de estas áreas está reglamentada por ley y existen incentivos de fomento estatal para su manejo sostenible. El país dispone de una fuerte y desarrollada industria forestal de celulosa y papel, aserrío, tableros y chapas, y otros productos. Esta capacidad industrial consume en el año 2019 un total de 45,3 millones de metros cúbicos de trozas y genera 5,3 millones de toneladas de pulpa, 7,9 millones de metros cúbicos de madera aserrada, 11,6 millones de metros cúbicos de astillas, 3,3 millones de metros cúbicos de tableros y chapas, y otros productos. Una gran parte esta producción forestal del país está destinada a mercados externos y en el año 2019 se genera un retorno de exportaciones de 5.662 millones de US\$ FOB (INFOR, 2020). El consumo anual de madera en trozas para fines industriales proviene fundamentalmente de las plantaciones forestales, solo el $0,5 \%$ de este se origina en los bosques nativos, y la tasa de reforestación anual está en torno a las 100 mil hectáreas (INFOR, 2020).

\section{- Manejo Forestal y Biodiversidad de los Bosques en Chile}

La reposición de las plantaciones forestales cosechadas anualmente se produce de inmediato, al año siguiente o subsiguiente. Normalmente los residuos de cosecha quedaban sobre el suelo, cubriéndolo y protegiéndolo de la erosión, luego se comenzó a utilizar parte de esta biomasa para energía por lo que la protección de los suelos era solo parcial, aunque por un periodo reducido hasta la expansión de las copas de los árboles. Se debe destacar además que esta reforestación es obligatoria por ley en el país. Respecto de los bosques nativos, de casi nula participación en la producción forestal actualmente, la política forestal de Chile regula, promueve, fomenta e incentiva económicamente su manejo sostenible. Se estima que aproximadamente la mitad de estos bosques tiene un potencial comercial, unos 7 millones de hectáreas, y está fundamentalmente en manos de pequeños y medianos propietarios, razón por la que su puesta en producción bajo manejo forestal sostenible sería de gran importancia social y económica. En la actualidad los bajos incentivos al manejo y la ejecución de las actividades de manejo por propietarios que apenas sobreviven de sus recursos, hacen que la producción sostenible este lejos de ser realidad en la mayor parte de los bosques nativos. Esta falencia lamentablemente genera efectos negativos de importancia sobre la biodiversidad.

La mayoría de las veces, se piensa que la ordenación ${ }^{27}$ forestal es incompatible con el mantenimiento de la biodiversidad, ya que los objetivos de la ordenación suelen estar dirigidos a un número limitado de especies de árboles. Por lo tanto, puede parecer razonable, a primera vista, plantear la hipótesis de que el manejo forestal invariablemente disminuye la diversidad del bosque. Sin embargo, la biodiversidad vegetal de los ecosistemas forestales está determinada por algo más que las especies dominantes del dosel superior, es decir, las especies de otros estratos forestales también contribuyen a la diversidad. Además, los efectos del manejo forestal en los patrones y mecanismos de diversidad pueden variar considerablemente entre los tipos de ecosistemas y las técnicas de manejo (Gilliam y Roberts, 1995). En este sentido, para que los bosques plantados contribuyan significativamente a la conservación de la biodiversidad en sus ecosistemas y sus funciones, es preciso sugerir algunas estrategias específicas de manejo forestal (Zaninovich, 2017). En Chile, el Ministerio de Medio Ambiente (MMA, 2019) indica que

\footnotetext{
${ }^{27}$ La ordenación forestal sostenible es "el proceso de manejar los bosques para lograr uno o más objetivos de ordenación claramente definidos con respecto a la producción de un flujo continuo de productos y servicios forestales deseados, sin reducir indebidamente sus valores inherentes ni su productividad futura y sin causar ningún efecto indeseable en el entorno físico y social".
} 
para el ámbito silvícola existen acciones voluntarias de privados, tales como códigos de buenas prácticas y certificaciones que contribuyen a la gestión sustentable de la biodiversidad y sus servicios ecosistémicos, los cuales se indica a continuación:

- El Protocolo de Plantaciones Forestales, elaborado por CONAF en el año 2017 para orientar a los propietarios de plantaciones forestales en el desarrollo de los planes de manejo normados, así como los planes de acción voluntarios. Se trata de un conjunto de pautas y estándares para el establecimiento y manejo de las plantaciones forestales con criterios de equidad, sustentabilidad y gestión del riesgo.

- La certificación CERTFOR, administrada por CERTFOR Chile, es reconocida y homologada por la organización internacional denominada Programa para la Homologación de Sistemas de Certificación Forestal (PEFC). Al adherirse a estos sistemas de certificación, las empresas se comprometen a no sustituir el bosque nativo y a conservar muestras representativas de los ecosistemas existentes en su propiedad. Otros criterios PEFC estipulan la sustitución o disminución de sustancias químicas, tales como pesticidas o herbicidas. Al año 2018 había un total de 1.909.713 ha certificadas, de las que 1.314.242 ha correspondían a plantaciones y 667.721 ha a otros tipos.

- La certificación FCS, administrada por Forest Stewardship Council, una organización internacional, no gubernamental, sin fines de lucro e independiente. FSC se rige por 10 principios y 56 criterios. El Principio № 9, Mantenimiento de Bosques con Alto Valor de Conservación, tiene como objetivo mantener o mejorar los atributos de conservación que definen a dichos bosques, por lo que tiene un impacto directo en la biodiversidad de los Recursos Genéticos Forestales. Además, los principios 6, Impacto Ambiental, y 7, Plan de Manejo, contienen criterios que colaboran en la mantención de la biodiversidad. Al año 2018 la organización presentaba 2.325.662 ha certificadas.

Atendiendo a las tendencias que existen en otros países sobre cómo mantener y mejorar aún más la biodiversidad en bosques plantados Horák, et al. (2019), establecen dos enfoques posibles:

- Aumentar la heterogeneidad de las especies arbóreas dentro de los rodales (es decir, a una escala espacial de unas pocas hectáreas), lo cual es importante para el manejo forestal individual apropiado.

- Mantener la vegetación nativa dentro de la matriz de los bosques de plantación (es decir, a escala espacial del paisaje), que es importante para el manejo forestal global. Con esto se pretende un ordenamiento forestal del territorio productivo, es decir, lograr un mosaico de distintos tipos de bosques, que no necesariamente ocupan la misma parte topográfica, plantaciones en terrenos menos frágiles, bosque nativo en quebradas y laderas escarpadas y cumbres.

Torras y Saura (2008) consideran que se debe tener presente el tipo de bioindicador de biodiversidad a utilizar, como, por ejemplo, árboles de gran diámetro, abundancia de arbustos, riqueza de especies de arbustos, riqueza de especies de árboles y diversidad de especies de árboles. También hay que tener presente que las perturbaciones intermedias ${ }^{28}$ producto de la acción del manejo forestal tienden a aumentar la diversidad de los bosques en ambientes mediterráneos. Los resultados de Torras y Saura (2008) muestran que los tratamientos de mejora del rodal, especialmente los raleos y podas, también tienen efectos positivos sobre los indicadores de biodiversidad. Es importante considerar que el manejo forestal también requiere una perspectiva del paisaje para mantener la biodiversidad (Franklin, 1993). Si solo las perturbaciones intermedias ocurrieran en todo el paisaje, sin variabilidad en el tamaño, frecuencia o intensidad, entonces la diversidad a nivel del paisaje probablemente se reduciría porque las especies que dependen de las perturbaciones extremas serían eliminadas (Gilliam y Roberts, 1995). Puettmann, et al. (2016), establecen que tradicionalmente las actividades silvícolas han sido evaluadas con base en sus impactos a escala de un rodal durante un periodo de cuarenta a cien años. Sin embargo,

\footnotetext{
${ }^{28}$ Esta hipótesis sostiene que en ecosistemas maduros la presencia de perturbaciones intermedias permite mantener niveles de riqueza de especies y de biodiversidad mayores a los que habría en ausencia de dichas perturbaciones. En ausencia de perturbaciones solo sería posible encontrar especies especialistas, en tanto que perturbaciones pequeñas no tendrían efecto alguno sobre la biodiversidad y perturbaciones grandes una disminución de la misma debido a la drástica destrucción del hábitat.
} 
muchos otros procesos que contribuyen a los fenómenos ecológicos, como la hidrología de suelos, la biodiversidad, el ciclo de carbono y la resiliencia, actúan en diferentes escalas espaciales y temporales (Figura 3).

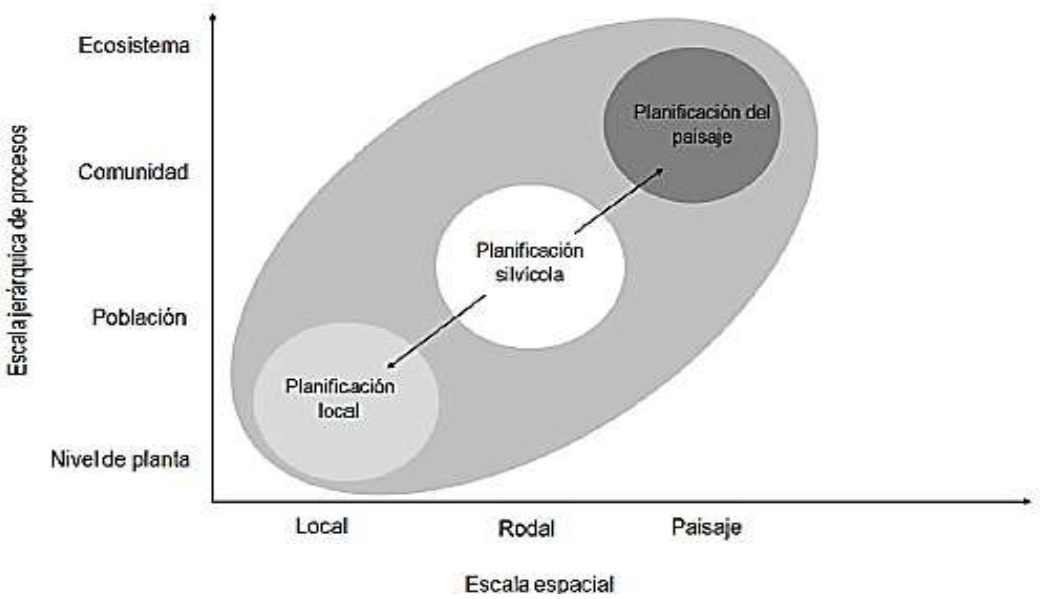

(Fuente: Puettmann, et al., 2016)

Los enfoques relacionados a temas silvícolas van desde la escala de rodal hasta la de paisaje.

Los enfoques que relacionan las prácticas silvícolas a la biodiversidad actúan de mejor forma a escala del paisaje.

Figura 3. Procesos y Escalas Espaciales Relacionadas con el Manejo Forestal

Los cambios en la heterogeneidad espacial y temporal, como por ejemplo abrir copas junto con perturbaciones naturales en las plantaciones forestales o dejar madera muerta dentro de los rodales, a escala del paisaje pueden ayudar a restaurar la biodiversidad forestal (Horak et al., 2014). Dejar parches naturales o seminaturales dentro de las plantaciones para que funcionen como islas de biodiversidad también puede ser una estrategia útil, y los árboles más añosos y dispersos pueden ser de enorme importancia para retener la biodiversidad (Horák, 2017). A esta estrategia de conservación de la biodiversidad de organismos saproxilicos ${ }^{29}$ conectada en corredores en la matriz productiva se la denomina "La Arteria de Biodiversidad Forestal" (Mason y Zapponi, 2015).

Es muy importante buscar opciones para mantener o mejorar la biodiversidad en los bosques plantados, FAO (2010) indica que este tipo de uso del suelo será dominante en el futuro, ya que se prevé un aumento de la demanda de los "productos" de las plantaciones, como la madera y la pulpa. Por lo tanto, las plantaciones deberán estar diseñadas, además para brindar mejores beneficios socioeconómicos a las comunidades humanas aledañas, como por ejemplo actividades de recreación y relajación, y producción de productos forestales no madereros, como colecta y producción de hongos y frutas silvestres, producción de miel, en plantaciones de eucalipto de baja densidad permitirán mejorar la biodiversidad, lo que será muy importantes en el futuro.

Para tener éxito, la silvicultura debe pasar del enfoque actual de manejo centrado en los rodales y considerar las plantaciones como parte del contexto más amplio del paisaje (Brockerhoff et al., 2008; Puettmann et al., 2016), particularmente sus funciones en procesos a escala de paisaje, por ejemplo, control de erosión y conectividad de remanentes de bosques naturales. Por último, al aceptar la necesidad de incorporar la biodiversidad en los procesos de planificación del manejo forestal de los bosques plantados, con criterios ambientales y económicos, permite utilizar herramientas de programación matemática, tal como la sugerida por Bertomeu y Romero (2001). Los autores mencionados

\footnotetext{
${ }^{29}$ Los organismos saproxílicos son aquellos que dependen, durante parte de su ciclo vital, de la madera muerta o senescente de árboles moribundos o muertos (en pie o caídos), o de hongos de la madera o de la presencia de otros saproxílicos
} 
sugieren formular un modelo de programación de cosecha que maximice el efecto de borde ${ }^{30}$ entre unidades de cosecha adyacentes, manteniendo al mismo tiempo las condiciones de crear rodales antiguos alargando la edad de rotación financiera y mantener un equilibrio de clases de edad, en el sentido de establecer el mismo número de rodales por clase de edad. De esta forma se obtendrá un cronograma óptimo a largo plazo desde el punto de vista de la biodiversidad.

\section{Monitoreo y Manejo del Territorio desde el Punto de Vista de la Gestión Forestal}

El marco del sistema de monitoreo es particularmente importante para tomadores de decisiones, ya que proporciona información útil para evaluar si las políticas y acciones propuestas han logrado (con determinada cantidad de fondos) resultados efectivos sobre la conservación de la biodiversidad (MMA, CTCN, CATIE e ICRAF, 2016). Esto se logra con la rendición de cuentas donde se incluyan el cumplimiento de los requisitos de información a nivel nacional e internacional. Para garantizar la priorización adecuada de las acciones de gestión y aumentar la eficiencia de las actividades de conservación, un sistema de monitoreo también debe proporcionar los medios para evaluar si las acciones y los recursos actuales son suficientes para alcanzar los objetivos de conservación acordados. El monitoreo de los bosques, referido al seguimiento en el tiempo de sus diferentes atributos, es fundamental para la toma de decisiones de manejo y conservación, y representa una tarea de relevancia estratégica para mantener los bienes y servicios que estos proveen, como a su vez la biodiversidad que sustentan (Corona, 2016).

Chile a solicitud del MMA, y desde el año 2012, forma parte de la Plataforma Intergubernamental sobre Servicios de Biodiversidad y Ecosistemas (IPBES), siendo esta la principal interfaz de diálogo entre ciencia y política a nivel global, equivalente en su rol al IPCC (Panel Intergubernamental de Cambio Climático). De acuerdo a Díaz et al. (2015) la Plataforma Intergubernamental sobre Biodiversidad y Servicios de los Ecosistemas (IPBES) fue establecida como un organismo intergubernamental independiente abierto a todos los países miembros de las Naciones Unidas, con el objetivo de fortalecer la interfaz ciencia-política para la biodiversidad y los servicios de los ecosistemas para la conservación y uso sostenible de la biodiversidad, bienestar humano a largo plazo y desarrollo sostenible (http://www.ipbes.net). Desarrollada a raíz de otras evaluaciones internacionales, específicamente la Evaluación de Ecosistemas del Milenio y el Panel Intergubernamental sobre el Cambio Climático (IPCC), la IPBES se diseñó para desarrollar de manera proactiva evaluaciones adaptadas a las necesidades de las políticas y para apoyar la creación de capacidad en todas las escalas y temas. Para lograr el objetivo mencionado, IPBES tiene cuatro funciones interconectadas (Díaz, et al., 2015; Álvarez y Durán, 2020): Catalizar la generación de nuevo conocimiento, producir evaluaciones de los conocimientos existentes, apoyar la formulación e implementación de políticas y desarrollar capacidades relevantes para lograr su objetivo. El primer producto público de IPBES fue un marco conceptual para respaldar todas estas funciones, estructurar las síntesis que informarán las políticas y mejorar la comparabilidad entre diversas evaluaciones realizadas en diferentes escalas espaciales, sobre diferentes temas y en diferentes regiones.

Vivanco Font (2019) establece que el primer informe de la Plataforma Intergubernamental CientíficoNormativa sobre Diversidad Biológica y Servicios de los Ecosistemas (IPBES), publicado en el 6 de mayo del año 2019, el más completo realizado hasta ahora, constató una pérdida de la biodiversidad a un ritmo sin precedentes a nivel global, al punto de detectar más de un millón de especies en peligro de extinción. Tres científicos de universidades chilenas participaron en el capítulo dedicado a las Américas y creen que la amenaza a la biodiversidad en Chile no afecta solo al medioambiente, sino que tiene profundas implicancias en el desarrollo económico y social de las comunidades. Tanto ellos como el MMA apuestan por agilizar la creación del Servicio de Biodiversidad y Áreas Protegidas.

En Chile hay 133 especies en peligro crítico de extinción. El informe además identifica las causas de la pérdida de biodiversidad: El ser humano y sus prácticas, como la deforestación (las especies han perdido su hábitat); la sobrepesca y el cambio climático (CC). Por ejemplo, la productividad agrícola se ha reducido en un $23 \%$ a nivel global, con un costo de entre US\$ 235 mil millones y US\$ 577 mil millones de la producción mundial anual agrícola, esto sería resultado de la pérdida de polinizadores.

\footnotetext{
${ }^{30} \mathrm{El}$ borde se ha definido como la zona de transición entre hábitats adyacentes. El borde es la frontera entre rodales adyacentes. El efecto de borde asume que la diversidad y abundancia de muchas especies de vida silvestre es mayor cerca de un borde.
} 
Otro sistema de monitoreo de la biodiversidad es el establecido por el Grupo de Observaciones de la Tierra, la Red de Observación de la Biodiversidad (GEO-BON), sugerido por Fischer et al. (2010). Esta es una red ampliada de plataformas de investigación de tipo exploratorio en Europa y el mundo que capturan los principales tipos de ecosistemas y permite una comprensión y una predicción mucho más mecanicistas de los cambios en la biodiversidad y la función de los ecosistemas que las múltiples y muy dispersas actividades que se llevan a cabo actualmente.

De acuerdo a Maass et al. (2019) la enorme gradiente de latitud y complejidad geográfica de Chile, así como su gran diversidad de climas y de ecosistemas, justifica la implementación de un Observatorio Nacional de Biodiversidad, cuyos objetivos fundamentales sean monitorear el estado de la biodiversidad y reportarlo a instancias locales, nacionales e internacionales (Convenio sobre la Diversidad Biológica) y predecir escenarios futuros para la biodiversidad en un marco de cambio climático. Ejemplos de observatorios nacionales de biodiversidad en pleno desarrollo se encuentran en Colombia y China, los que se han acogido al marco de GEO-BON. En ambos casos existe financiamiento nacional e internacional para su implementación y, aunque los directores y contribuidores de datos provienen principalmente de universidades, centros de investigación y servicios públicos, la red nacional es en última instancia coordinada y financiada por el Estado. En paralelo al desarrollo de iniciativas globales, orientadas a compilar grandes volúmenes de datos de biodiversidad, varios países han desarrollado sistemas de información vinculados a iniciativas globales con portales de datos de acceso abierto, en línea y colaborativos, que albergan información de especies (descripciones con imágenes, distribución, hábitat, categorías de riesgo), registros de presencia (especímenes, observaciones), datos ambientales (datos de clima, topografía, biogeoquímica) y contextuales (límites políticos, áreas protegidas, ecorregiones).

En las mismas plataformas se pueden entregar herramientas para la visualización de datos (mapas de distribución), modelamiento y análisis de datos, además de productos ya procesados (por ejemplo, fichas de especies) (Maass et al., 2019). La iniciativa Global Biodiversity Information Facility (GBIF), creada en 2001 por los gobiernos de la OCDE, es un sistema distribuido de acceso abierto, con diversos proveedores de datos, que son responsables de la calidad y el control total de los datos. En Chile, el MMA $^{31}$ es responsable del Nodo Nacional de Información sobre Biodiversidad, GBIF Chile. El nodo, que está operativo desde 2016, busca articular y fomentar la captura y registro de calidad de los datos sobre biodiversidad en el país, aportar herramientas técnicas para la administración de datos biológicos, impulsar la colaboración entre iniciativas nacionales e internacionales relacionadas con datos de biodiversidad y gestionar financiamientos potenciales en el área (Maass et al., 2019).

A nivel de bosques nativos, de acuerdo a Miranda et al. (2018), en el año 1994 se inició en Chile el desarrollo del primer sistema nacional de cartografía de usos y coberturas del suelo, denominado "atastro y Evaluación de los Recursos Vegetacionales Nativos (catastro). Este sistema permitió construir una base de datos cartográfica oficial de la superficie de bosques y otros usos y/o coberturas del suelo. Sus resultados permitieron determinar, por primera vez, la superficie y distribución espacial de los bosques nativos a escala nacional, usando una metodología estándar para todo el territorio. La realización del catastro posibilitó además la caracterización de los bosques nativos en función de su estructura (por ejemplo: Bosque adulto, renoval, bosque achaparrado), tipo forestal, especies dominantes y grado de intervención. El catastro fue diseñado como línea base de una herramienta de seguimiento temporal de la superficie y distribución de los bosques, dando inicio a un sistema cartográfico inédito de monitoreo forestal nacional. Dado el largo proceso de ejecución de este sistema de monitoreo en Chile, Miranda et al. (2018) realizaron una revisión de los informes y datos oficiales a través de tres criterios básicos que deben poseer los sistemas de monitoreo forestal: i) Comparabilidad, ii) Replicabilidad y iii) Calidad. Dichos autores concluyen que la estimación de cambios en la cobertura de bosque nativo encuentra limitaciones, generando incertidumbre y controversia entre los diferentes actores. Sus resultados muestran que los cambios en la superficie de los bosques nativos se deben principalmente a cambios metodológicos y no a cambios reales. No obstante, al parecer nunca han existido cambios en la metodología, pero sí una adecuación tecnológica que va desde la fotogrametría tradicional al uso de georeferenciación e imágenes satelitales, lo que ha permitido que se perfeccionara la base geográfica donde se monta el catastro, iniciándose por ende un proceso de corrección del geoposicionamiento de

\footnotetext{
${ }^{31}$ Sitio web del Nodo Nacional de Información sobre Biodiversidad, Ministerio del Medio Ambiente de Chile, disponible en https://gbifchile.mma.gob.cl.
} 
los polígonos de uso del suelo por los años 2000. Por lo tanto, el contenido del polígono producto de una determinada actividad refleja el cambio de uso, como por ejemplo cosecha de plantaciones, terrenos agrícolas, que se convierten en matorral, matorrales que pasan a la agricultura. Todo esto sobre una base con geoposicionamiento corregido, luego la estadística de cambio es real ${ }^{32}$.

A nivel de ecosistemas, destaca la implementación del Sistema Integrado de Monitoreo de Ecosistemas Forestales (SIMEF) ${ }^{33}$, el cual fue financiado por el Fondo para el Medio Ambiente Mundial (GEF), implementado por la Organización de las Naciones Unidas para la Alimentación y la Agricultura (FAO), tiene como organismo ejecutor al Instituto Forestal (INFOR) y como co-ejecutores a la Corporación Nacional Forestal (CONAF) y el Centro de Información de Recursos Naturales (CIREN). SIMEF es ahora sostenido por el Ministerio de Agricultura del Gobierno de Chile, el cual incluye los aspectos de ocurrencia y abundancia de especies de flora, vertebrados e invertebrados en bosques nativos y formaciones xerofíticas del país. SIMEF ${ }^{34}$, establece unidades de muestreo del inventario continuo de ecosistemas vegetacionales que están contenidas en las unidades hexagonales de biodiversidad, de acuerdo a un diseño tal que asegure estimaciones insesgadas en la medida de lo posible. El número potencial de unidades de muestreo dentro de cada polígono se determina por la presencia de la malla sistemática país de $5 \times 7 \mathrm{~km}$ generando un máximo de 91 puntos/polígono, en que cada punto representa 1 ha., este número de unidades dependerá de la presencia de hábitats disponible para la existencia de los grupos objetivos. Por último, dentro del contexto de acciones voluntarias de las empresas forestales acogidas al sello de Manejo Forestal Sustentable de FSC destaca el protocolo de las Áreas de Alto Valor $(\mathrm{AVC})^{35}$, que permiten identificar, manejar y monitorear paso a paso para biodiversidad y AVC en bosques de pequeña escala con manejo de baja intensidad (Unda, 2016) (Figura 4).

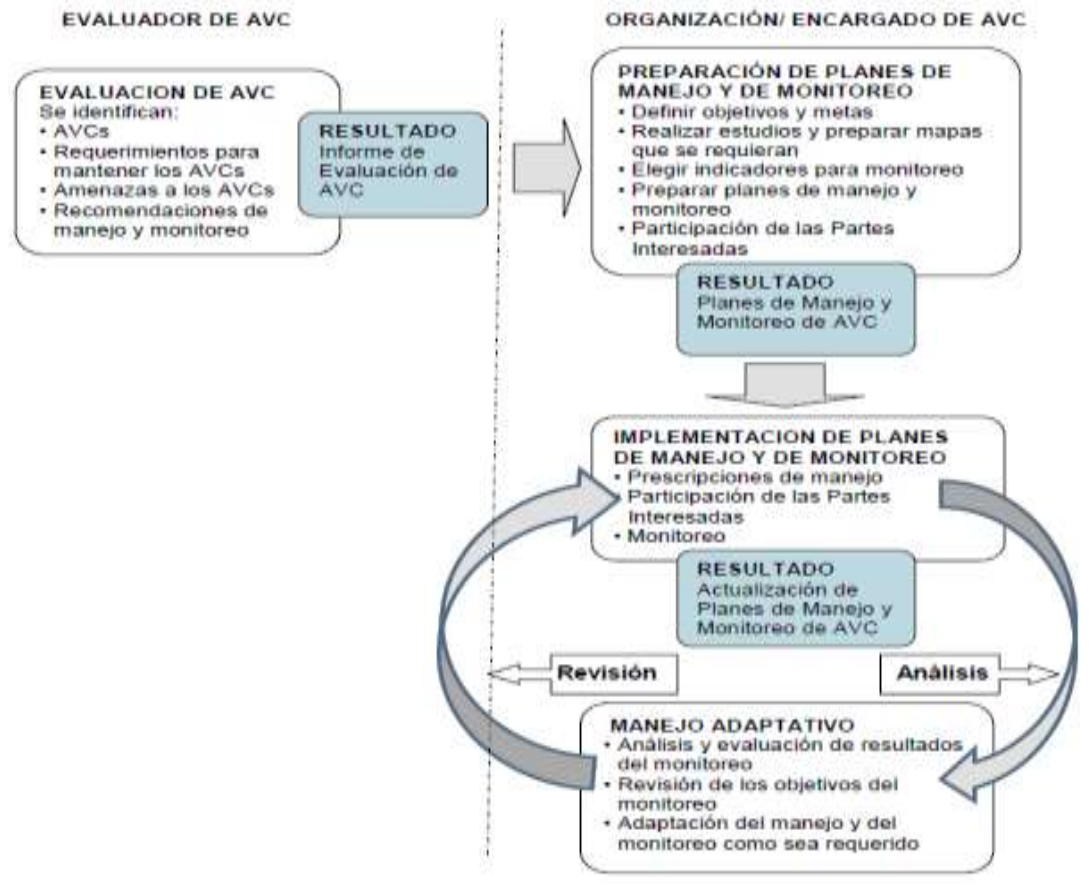

(Fuente: Unda, 2016)

Figura 4. Proceso de Identificación, Manejo y Monitoreo de AVC

\footnotetext{
32 Verónica Oyarzun, 2021. Comunicación personal

${ }^{33}$ Sitio web del Sistema Integrado de Monitoreo de Ecosistemas Forestales, disponible en https://simef.minagri.gob.cl/.

${ }^{34} \mathrm{https}: / /$ simef.minagri.gob.cl/bibliotecadigital/bitstream/handle/123456789/12938/BIODIVERSIDAD\%20PROTOCOLO\%20MZ\%20T EMPLADA.pdf?sequence $=1$ \&isAllowed $=\mathrm{y}$

35 Área de Alto Valor ecológico: Se refiere a toda área que posea valor relevante para la biodiversidad. En este sentido, el término puede usarse para una amplia gama de espacios, tales como: ecosistemas terrestres, ecosistemas acuáticos, islas oceánicas, áreas de restauración, núcleos de biodiversidad, infraestructura ecológica, corredores biológicos, entre otros.
} 


\section{Conservación de la Biodiversidad en las Áreas Protegidas Públicas y Privadas de Chile}

El concepto de área protegida data de cientos de años, no obstante, aunque originalmente fueron concebidas para conservar paisajes de belleza relevante y fauna emblemática, en la actualidad se espera que su conservación logre un conjunto grande y diverso de objetivos ambientales, sociales y económicos (CDB, 2011). Es considerada como la mejor y única estrategia para conservar la biodiversidad in situ, sin embargo, su financiamiento a nivel mundial y nacional es cada vez menor. El movimiento moderno de conservación de parques nacionales y otras áreas protegidas tuvo sus inicios en el siglo XIX en Norte América, Australia, Europa y Sudáfrica estableciéndose en lugares de rasgos naturales espectaculares para proteger fauna icónica, principalmente en terrenos con poco potencial para uso económico (Hendee y Dawson, 2009). A estas iniciativas de conservación no escapan los países sudamericanos y Chile también se une a esta corriente al establecer sus primeras reservas y parques nacionales a principios del siglo XX.

\section{- Áreas Protegidas Estatales}

El establecimiento de las áreas protegidas en Chile está estrechamente vinculado al sector forestal, a las ciencias forestales y principalmente a la conservación de los bosques. La creación de reservas fiscales y de parques nacionales en su origen legal e institucional así lo indica. Aunque hubo alguna legislación para conservar territorios que protegiesen bosques y aguas a fines del siglo XVIII (Weber y Gutiérrez, 1985) y una activa labor de pioneros como Federico Albert, no fue hasta septiembre de 1907 que se dio un paso importante en la conservación ambiental, cuando mediante el decreto supremo $\mathrm{N}^{\circ} 1540$ del Ministerio del Interior se estableció legalmente la Reserva Forestal Malleco, que es la primera unidad territorial con límites claros y definidos, y administrada por personal residente encargado de dicha función. Durante los años siguientes y hasta 1913, fueron creadas las reservas forestales de Tirúa, Villarrica, Alto del Bio Bio, Llanquihue, Petrohué, Puyehue y Chiloé, con un total de 600.000 ha distribuidas entre Concepción y Puerto Montt (Pauchard y Villarroel, 2002). Cuando en 1925 se crea el Parque Nacional Benjamín Vicuña Mackenna, en la provincia de Cautín, Chile se convierte en uno de los primeros países de América Latina en establecer oficialmente un Parque Nacional. Aunque tuvo corta duración (4 años) sentó las bases para una toma de consciencia de conservar el patrimonio natural con fines de uso y bienestar público. Esto no fue obstáculo para que en 1926 se estableciera el Parque Nacional Vicente Pérez Rosales, con una superficie de 135 mil hectáreas en la provincia de Llanquihue, unidad que se mantiene hasta hoy. El Decreto Ley 4.363 de 1931, conocido como Ley de Bosques, otorgó al Presidente de la República la facultad de establecer parques nacionales de turismo y reservas forestales. Hasta el año 1965 se habían establecido 26 parques nacionales con una superficie aproximada de 11,5 millones de hectáreas, entre ellos Archipiélago Juan Fernández y Rapa Nui (CIPMA, 2003). En el año 1966 se establecen cinco parques nacionales más adicionando 111.000 ha, entre ellos Laguna de los Cisnes en Magallanes y Punta del Viento en Coquimbo. Además, ese mismo año se crearon cinco reservas forestales con 487.000 ha. Por lo que, a esa época, Chile ya contaba con 2,2 millones de hectáreas de superficie afecta al régimen de conservación oficialmente protegida por el Estado. Un hito clave de apoyo gubernamental fue que en 1967 el gobierno de Chile ratificó la Convención de Washington de 1940, acuerdo internacional para la Protección de la Flora, Fauna y de las Bellezas Escénicas Naturales de los Países de América. Posteriormente entre 1970 y 1974 se establecieron otros 12 parques nacionales y 3 reservas forestales; esto constituyó el inicio de un activo proceso de adición de áreas silvestres protegidas, que culminaría con la creación del Sistema Nacional de Áreas protegidas del Estado (SNASPE) en 1984.

Cabe señalar que hasta la década de 1970 eran varios los organismos del Estado que podían crear y manejar áreas silvestres protegidas, siendo el más importante el Servicio Agrícola y Ganadero (SAG). En esa misma década le fue asignada a la Corporación Nacional Forestal (CONAF) la administración de casi todas las áreas protegidas del país. Sin embargo, no hubo una legislación que integrara todas las áreas en un sistema nacional hasta 1984, año en que se promulgó la Ley № 18.362 que crea el SNASPE (Diario Oficial de Chile, 1984). Pero, es necesario destacar que el artículo 39 de dicha Ley, establece que ella no puede entrar en vigencia, en tanto no lo haga la Ley № 18.3484, que crea la Corporación Nacional Forestal y de Protección de Recursos Naturales Renovables, lo que aún en el año 2021 continúa pendiente. Su objetivo fue organizar todas las áreas silvestres protegidas del país en un Sistema Nacional que tuviera el propósito común de proteger el patrimonio natural. En ella se establece que este estará integrado por cuatro categorías de manejo: Parques Nacionales, Reservas Nacionales, 
Monumentos Naturales y Reservas de Región Virgen. CONAF ha sido una institución relevante en la historia de la administración de las áreas silvestres protegidas del Estado en el ámbito de los ecosistemas terrestres. Fue creada como un órgano de derecho privado, sin fines de lucro y subordinado al Ministerio de Agricultura. Sus principales funciones son el fomento forestal, el combate y control de incendios forestales y la administración de Áreas Silvestres Protegidas del Estado en el ámbito terrestre. Como se señaló, en 1984, la ley №18.362 establecía la creación del SNASPE, sin embargo, dicha ley no entró en vigencia ya que quedó supeditada a la creación de la Corporación Nacional Forestal y de Protección de Recursos Naturales Renovables, como servicio público descentralizado, cuestión que no se materializó. En razón a lo anterior, las Áreas Silvestres Protegidas del Estado se sustentan legalmente en la Ley de Bosques de 1931, en el D.S. № 531 de 1967, que ratifica la Convención de Washington de 1940 y en el D.L. № 1.939 de 1977, sobre adquisición y administración de bienes del Estado (MMA, 2015). En etapas posteriores se fusionaron varios grupos de áreas protegidas entre sí y se desafectaron otras o parte de ellas sin afectar significativamente la superficie total del sistema. La activa adición de nuevos terrenos al sistema durante ese periodo se caracterizó porque estos se concentraron preferentemente en el extremo sur del país, y se protegieron en parte, suelos frágiles del sector de los canales, muy susceptibles de sufrir degradación por acción humana (CIPMA, 2003).

En el año 1983 CONAF llevó a cabo un proceso de reclasificación de categorías de manejo de sus unidades, ampliación de deslindes y desafectación de territorios de la condición de Parque Nacional, Reserva Nacional y Monumento Natural, ello con el propósito de mejorar no solo la representatividad ecológica, sino que también adecuar los conceptos de las categorías de manejo con las características naturales de las unidades.

En la actualidad, uno de los criterios que ha establecido CONAF para la creación de áreas silvestres protegidas es incorporar muestras representativas de la biodiversidad de Chile o mejorar su representación en el SNASPE, mediante diferentes orientaciones que entregan estudios científicos (CONAF, 2017). El Sistema, eminentemente terrestre, hasta hoy es administrado por la Corporación, cuenta con 105 áreas protegidas distribuidas a lo largo y ancho de Chile con representatividad de gran parte de la biodiversidad del país, como son las zonas desérticas, las áreas naturales asociadas al patrimonio cultural, zonas de canales con glaciares y fiordos, bosques lluviosos del sur, cadenas de volcanes, la Patagonia chilena y otras muestras únicas de la variedad de paisajes y ecosistemas que evidencian la potencialidad para la conservación de la naturaleza, cubriendo más del $19 \%$ del territorio nacional continental (De la Maza y Rodríguez, 2010).

A mediados de la década de 1990, el auge del desarrollo sostenible y los temas relacionados con el medio ambiente en la agenda internacional culminó a nivel nacional con la aprobación de la Ley de Bases Generales sobre el Medio Ambiente (Ley № 19.300, 1994) y la creación de la Comisión Nacional de Medio Ambiente (CONAMA) como ente coordinador de las distintas instituciones del Estado con competencias relacionadas con el medio ambiente. Asimismo, en el marco de la adhesión del CDB (1992), Chile diseñó y aprobó en 2003 una Estrategia Nacional de Biodiversidad y un Plan de Acción Nacional orientados a conservar y dar uso sostenible a los ecosistemas terrestres y marinos.

\section{- Áreas Protegidas Privadas o Iniciativas Privadas de Conservación}

Las áreas protegidas privadas están contempladas en la Ley de Bases Generales del Medio Ambiente (Ley 19.300 de 1994) y en su modificación, la Ley 20.417, que Crea el Ministerio de Medio Ambiente, el Servicio de Evaluación Ambiental y la Superintendencia del Medioambiente, en ambas leyes en el artículo 35 se indica que "el Estado fomentará e incentivará la creación de áreas silvestres protegidas de propiedad privada, las que estarán afectas a igual tratamiento tributario, derechos, obligaciones y cargas que las pertenecientes al Sistema Nacional de Áreas Silvestres Protegidas del Estado". La afectación de ellas es de carácter voluntario, debieran tener un rol complementario al SNASPE y tienen los mismos propósitos que las áreas silvestres de protección estatal, es decir deben asegurar la diversidad biológica, tutelar la preservación de la naturaleza y conservar el patrimonio ambiental. La supervisión de estas áreas protegidas privadas corresponde al Servicio de Biodiversidad y Áreas Protegidas (Ley 20.417, artículo 35, inciso 2).

En forma creciente, a partir de la última década del siglo $X X$, se han creado en Chile numerosas áreas silvestres protegidas de propiedad privada. Se estima que en la actualidad su superficie total bordea el millón de hectáreas, ubicadas en su mayoría en el sur del país, entre las regiones de Los Lagos y 
Magallanes. Las áreas protegidas privadas tienen tamaños muy diversos, van desde algunas hectáreas hasta centenares de miles de hectáreas. Las áreas privadas de gran tamaño en algunos casos pueden contribuir a mejorar la cobertura de las formaciones vegetales ausentes o subrepresentadas en el SNASPE en la actualidad, mientras que las áreas de menor tamaño pueden constituirse en corredores biológicos que aumenten la conectividad entre las áreas de gran tamaño.

En los últimos años también se han estado llevando a cabo esfuerzos significativos en el ámbito marino, con la creación de Parques Marinos, Reservas Marinas y Áreas Marino Costeras Protegidas de Múltiples Usos. Asimismo, existen las figuras de Santuarios de la Naturaleza y Bienes Nacionales Protegidos. Los Santuarios de la Naturaleza pueden ser públicos o privados y los Bienes Nacionales Protegidos son de propiedad fiscal, cuyo mecanismo de gobernanza es público-privado basado en la entrega de concesiones a largo plazo para la gestión y administración por privados.

El año 2010, con la modificación de la Ley de Bases Generales del Medio Ambiente (Ley № 20.417, 2010) se reformó profundamente la institucionalidad ambiental, creando el Ministerio de Medio Ambiente (MMA) como "una Secretaría de Estado encargada de colaborar con el Presidente de la República en el diseño y aplicación de políticas, planes y programas en materia ambiental, así como en la protección y conservación de la diversidad biológica y de los recursos naturales renovables e hídricos, promoviendo el desarrollo sustentable, la integridad de la política ambiental y su regulación normativa".

Asimismo, esta reforma comprometió la creación de un servicio público encargado de la conservación de la biodiversidad y, en particular, de la administración de las áreas protegidas del país. Por lo que, en junio de 2014, el ejecutivo ingresó al Congreso el Proyecto de Ley que crea el Servicio de Biodiversidad y Áreas Protegidas y el Sistema Nacional de Áreas Protegidas (proyecto de ley del SBAP), actualmente aún en tramitación en el Congreso Nacional. Este proyecto de ley tiene por objeto la conservación de la diversidad biológica del país, a través de la preservación, restauración y uso sustentable de las especies y ecosistemas. Su aprobación permitirá implementar de manera integral políticas, planes, programas y normas para la conservación de la biodiversidad, tanto fuera como dentro de las áreas protegidas, de manera orgánica y consecuente con los compromisos adquiridos en el marco del CDB, el Plan Estratégico para la Diversidad Biológica (2011-2020) y otras convenciones, además de las recomendaciones de la OCDE en materia de conservación de la naturaleza (MMA, 2015).

Sin tener el carácter de áreas protegidas, existen los denominados Sitios Prioritarios para la Conservación de la Biodiversidad. Estos sitios surgen a comienzos de la década del 2000 de un trabajo realizado en cada una de las regiones de Chile, al amparo de los Comités Regionales de Biodiversidad, coordinados por la entonces Comisión Nacional del Medio Ambiente (CONAMA), sumando un total de 338 sitios con una superficie aproximada de aproximadamente 13,8 millones de hectáreas a nivel nacional. Un sitio prioritario es un área terrestre, marina o costero-marina de alto valor para la conservación y uso sustentable de la biodiversidad, identificada por su aporte a la representatividad ecosistémica, su singularidad ecológica o por constituir hábitat de especies amenazadas (MMA-GEFPNUD, 2016). Estos sitios son considerados como de alta prioridad para la protección o restauración y pueden ser de propiedad pública o privada. En una porción muy significativa de estos sitios la propiedad de la tierra es fundamentalmente privada o comunitaria. Las presiones por uso del espacio son fuertes, marcadas por el crecimiento poblacional del país y por su expansión productiva. Probablemente la solución sea desarrollar métodos de producción que permitan la coexistencia de la vida biológica, bajando el uso de pesticidas y variando el esquema extensivo a uno de mosaicos intensivos.

Por lo tanto, se ha hecho evidente en Chile, en forma concordante con la tendencia mundial, que es necesario integrar nuevos mecanismos y actores a la conservación de la biodiversidad. Entre ellos, destaca la posibilidad de reconocimiento, como áreas protegidas, de las iniciativas de conservación privada y de pueblos originarios, pues tienen el potencial de abarcar una amplia diversidad de ecosistemas y con ello proveer de diversos servicios ecosistémicos a la sociedad (MMA-GEF-PNUD, 2016).

En este escenario, las iniciativas de conservación privada pueden constituirse en una herramienta fundamental de una estrategia de conservación de la biodiversidad a largo plazo, contribuyendo a cubrir los vacíos de protección de ecosistemas, especies y funciones ecológicas, o bien favoreciendo la conectividad territorial y biológica en áreas protegidas ya existentes. De este modo, la participación privada es indispensable en el diseño y despliegue temprano de un Sistema Nacional Integral de Áreas 
Protegidas, públicas y privadas, terrestres y marinas, particularmente en la definición de sus objetivos estratégicos y metas.

Sin embargo, el conjunto de áreas protegidas actualmente existentes en el país no logra representar de manera adecuada todas las ecorregiones y ecosistemas existentes, persistiendo aún importantes vacíos de protección, particularmente en la zona mediterránea del país. Es por ello que existen numerosos desafíos para consolidar la conservación de la biodiversidad y de la naturaleza en el país y, para ello, un servicio de áreas protegidas sostenible en todos sus ámbitos es un paso importante a lograr. Asimismo, es relevante abordar los desafíos planteados desde una perspectiva sistémica para el establecimiento, la gestión y el monitoreo de las áreas protegidas, mediante un sistema nacional sólido y moderno y que cuente con las herramientas financieras y legales, necesarias para el cumplimiento de sus funciones y competencias.

En este contexto, algunos desafíos sugeridos se enfocan en los siguientes ámbitos: Fortalecer la institucionalidad principalmente desde el punto legal; fortalecer la planificación adaptativa desde un punto de vista estratégico; fortalecer la representatividad y conectividad de las áreas protegidas; fortalecer las relaciones público-privadas y de actores no estatales en la gestión de la conservación; incrementar recursos para la investigación en los diferentes niveles de protección y gestión de ellas; y desarrollar o establecer un sistema regional de áreas protegidas.

Debido a que la conservación y la gestión de la biodiversidad, ya sea pública o privada, es una tarea inter y transdisciplinaria, que compete a todas las disciplinas y a toda la sociedad, es evidente que la participación de las ciencias forestales, de la ingeniería forestal y del sector que las representa, seguirá teniendo un rol significativo en su gestión, contribuyendo así al desarrollo sostenible de Chile.

\section{Conservación de la Biodiversidad y Adaptación al Cambio Climático}

Desde el año 2000 existía el convencimiento que el cambio climático sería una de las principales causas de la pérdida de biodiversidad en todo el mundo (Sala et al., 2000), además había evidencia convincente de que el cambio climático produciría la extinción de especies de muchos taxones (Thomas et al., 2004). En relación a las pérdidas de especies habría que hacer énfasis en la afectación o desplazamientos o la extinción local de poblaciones de especies polinizadoras y de controladores biológicos de plagas y enfermedades (FAO, 2008).

La longevidad que poseen los árboles y los ecosistemas forestales de los que forman parte les confiere una capacidad de adaptación limitada para responder a cambios ambientales rápidos (Lindner et al., 2010) y, por lo tanto, son particularmente sensibles al cambio climático. Además, la longevidad de los árboles, la extensión de los bosques y la falta de especialistas en terreno hacen pasar desapercibido los sutiles y pequeños cambios iniciales hasta que se han producido cambios importantes y muchas veces irreversibles. Pawson et al. (2013) recopilan las alteraciones que provoca el cambio climático en el bosque, los que se pueden resumir en: la abundancia relativa de especies de árboles dentro de los bosques; fenología del árbol, tal como la estacionalidad de la floración, brotación y fructificación; alteración de la dinámica productor-herbívoro; frecuencia e intensidad de los mecanismos clave de perturbación forestal, incluidos los eventos de daño por viento e incendios; y la dinámica poblacional de plagas y patógenos forestales.

Si bien muchos de estos mecanismos se han estudiado en bosques naturales y seminaturales, los conceptos generales también son relevantes para los bosques de plantación. Al comparar los efectos de estas alteraciones sobre las plantaciones y los bosques naturales aparentemente se deberían diferir, ya que las plantaciones están dominadas normalmente por una o pocas especies de árboles con una diversidad genética limitada, lo que puede convertirlos en más susceptibles a las consecuencias del cambio climático, como la dinámica cambiante de las plagas y enfermedades forestales. No obstante, la intensidad del cambio climático y la degradación genética producto de la selección disgénica o "floreo" en bosques naturales puede hacer que estas diferencias no sean tan distintas en algunas áreas.

Ahora, dado que la forestación, la reforestación y la restauración ecológica forestal son las estrategias claves para mitigar el cambio climático (Pawson et al., 2013), es fundamental incorporar a las nuevas plantaciones, tanto de especies nativas como de exóticas, la suficiente variabilidad genética adaptativa para anticiparse a los efectos del cambio climático sobre la supervivencia y su capacidad de proporcionar hábitat para la biodiversidad. 
Las plantaciones de bosques que reemplazan la vegetación natural generalmente causan pérdidas de biodiversidad a nivel local, y no son aceptadas por los sellos de Manejo Forestal Sustentable, Forest Stewardship Council (FSC) y Programa para el Reconocimiento de la Certificación Forestal (PEFC CHILE), en cambio, las plantaciones establecidas en tierras agrícolas o degradadas brindan oportunidades importantes para la conservación de la biodiversidad. Por lo tanto, el impacto de los bosques plantados sobre la biodiversidad dependerá del uso de la tierra que reemplacen y de la intensidad del manejo forestal.

Pawson et al. (2013) mencionan que el potencial de los bosques naturales no manejados para adaptarse a los impactos del cambio climático es algo limitado, particularmente cuando la dispersión de las especies que la componen tiene restricciones biológicas y/o modificaciones antropogénicas de paisajes (degradación y fragmentación entre otros). Sucede algo similar en relación con el rápido cambio en los parámetros climáticos, tales como la temperatura más cálida del mes de enero, la temperatura mínima del mes de julio y el estrés hídrico (Santibañez y Santibañez, 2018), donde los arboles no pueden adaptarse a estos rápidos cambios y quedan totalmente desacoplados de su ambiente.

Por el contrario, el potencial de adaptación de las plantaciones forestales es mucho mayor, ya que los silvicultores pueden alterar los regímenes silvícolas y la composición de las especies de árboles para mantener la capacidad productiva y, por lo tanto, económica de estos bosques para adaptarse o mitigar los efectos del cambio climático.

Como resultado, el impacto del cambio climático sobre la biodiversidad en los bosques plantados será el producto de una interacción entre los impactos directos del cambio climático y los efectos indirectos de los nuevos enfoques de gestión adoptados para abordar estos impactos previstos. Esto justifica un análisis en profundidad de los impactos del cambio climático con un enfoque actual y futuro sobre los bosques plantados (Paquette y Messier, 2010).

La provisión de madera y otros productos derivados de la madera de las plantaciones forestales proporciona un beneficio indirecto significativo a la biodiversidad al reducir la necesidad de extraer recursos de los bosques naturales (Brockerhoff et al., 2008). Pawson et al. (2013) también identifican los impactos potenciales del cambio climático sobre la biodiversidad de las plantaciones actuales. Para el caso Chile, solo se mencionan las más importantes, ya que se ha escrito muchos informes y publicaciones al respecto:

- Impactos climáticos: Lo más relevante quizás sean los factores de predisposición sobre la vitalidad de la Araucaria araucana y sobre el bosque esclerófilo.

- Impacto de plagas y enfermedades: Vale mencionar el daño foliar del pino ocasionado por Phytophthora pinifolia.

- Impacto de los incendios forestales: Las sequias extremas y locales facilitan la acción de los causantes de estos grandes destructores de la biodiversidad.

Para adaptarse al cambio climático y minimizar sus potenciales impactos sobre la biodiversidad se ha sugerido que los bosques naturales deben manejarse con estrategias de baja intensidad de manejo para que a través de la regeneración natural o asistida puedan originar una progenie que pueda sobrevivir y de esta forma expresar de mejor forma la variación genética adaptativa.

En la silvicultura europea se ha perfeccionado y promovido esta técnica de manejo sustentable de los bosques a través del concepto de PROSILVA ${ }^{36}$ (Wolynski, 2002) o Gestión Forestal Próxima o Cercana a la Naturaleza. Las aplicaciones prácticas en Chile han sido implementadas por APROBOSQUE A.G ${ }^{37}$ y una muestra operacional es el establecimiento de la regeneración natural en el tipo forestal Roble-RaulíCoigüe (Müller-Using et al., 2014). Los árboles que compiten y sobreviven se convertirán a lo largo del tiempo en los futuros progenitores de los bosques naturales del futuro, este proceso no es de corto plazo, requiere de adecuados recursos financieros y técnicos, e incentivos económicos por parte del Estado y una nueva generación de silvicultores que manejen los bosques con una perspectiva de largo plazo.

${ }^{36}$ PROSILVA es una unión de forestales que conciben y aplican una silvicultura próxima a naturaleza. Esta unión fue fundada en Eslovenia en 1989.

${ }^{37}$ APROBOSQUE AG, es la asociación gremial de propietario de bosque nativo de Chile. 
En el caso de las plantaciones, normalmente se las somete a una alta intensidad de manejo. Para prepararse para el cambio climático se ha sugerido una variedad de estrategias de mitigación y adaptación (FAO, 2012), como por ejemplo:

- A nivel del rodal, se puede establecer una mayor diversidad de especies de cultivo lo que puede mantener la capacidad de adaptación manteniendo tanto la producción de madera como la biodiversidad. Existe una resistencia de muchos forestales a no considerar plantaciones de especies mixtas, ya que se tiene la percepción de que reduce el rendimiento (Knoke et al., 2008) y complica las operaciones de manejo forestal. Sin embargo, existen cada vez más pruebas en los bosques naturales (Paquette y Messier 2011) y en las plantaciones (Plath et al., 2011) de que la diversidad de árboles puede mejorar o no tiene un efecto perjudicial sobre la productividad. Las plantaciones mixtas tienen el beneficio adicional de que es probable que sean más resistentes a los futuros desafíos sociales (culturales y económicos) y ambientales (estabilidad frente al cambio global, conservación de la biodiversidad), y al cambio climático. Las plantaciones mixtas también pueden tener algunas ventajas financieras que las hacen más atractivas, especialmente para los pequeños propietarios (Paquette y Messier, 2010; Pawson, et al., 2013).

- A nivel del paisaje, se puede lograr una mayor diversidad utilizando mosaicos de parches o corredores de bosques naturales remanente o restaurados, por ejemplo, en quebradas 0 plantaciones de diferentes especies, o incluso simplemente variando la edad del rodal y la longitud de rotación (Lamb, 1998; Paquette y Messier, 2010). Los resultados de la conservación de la biodiversidad al cambiar la composición del dosel de solo una especie (monocultivo) a otras dependerán del contexto. Si bien algunas especies de árboles proporcionan hábitat para especies particulares (de aves, mamíferos, insectos y plantas del sotobosque), un cambio en las especies de árboles plantados puede ser perjudicial para estas especies, pero potencialmente beneficioso para una variedad de otras especies a nivel del paisaje.

- Otras técnicas o acciones utilizadas para conservar o mejorar la biodiversidad ante la presión del cambio climático son: Cultivar el sotobosque (berries nativos, setas, entre otros), aumentar la edad y longitud de la rotación, control de malezas, raleo, podas, promover el hábitat de invertebrados saproxílicos, cortafuegos, franjas ribereñas, amortiguadores de carreteras, instalación de colmenas en plantaciones de especies entomófilas, entre otros.

Si bien se sabe que el cambio climático influye en la conservación de los ecosistemas, puede decirse, a su vez, que la conservación de los ecosistemas contribuye a enfrentar el cambio climático, en tal sentido, el Enfoque de Adaptación Basada en Ecosistemas, se fundamenta en la conservación, restauración y utilización sostenible de la biodiversidad y los servicios ecosistémicos que permiten a las personas adaptarse a los efectos adversos del cambio climático, manteniendo o aumentando la resiliencia y reduciendo la vulnerabilidad de los ecosistemas a través de su restauración y protección (Lhumeau Cordero, 2012).

La Adaptación Basada en Ecosistemas debiera formar parte de una estrategia más amplia de adaptación, constituyendo soluciones naturales y costo-efectivas de adaptación al cambio climático, además de beneficios sociales, económicos, ambientales y culturales (MMA, 2014b).

Sin lugar a dudas, el cambio climático tendrá efectos directos sobre la biodiversidad futura de los bosques naturales y las plantaciones debido a los cambios en los equilibrios regionales de temperatura y humedad. Sin embargo, en el corto a mediano plazo las acciones de manejo forestal que probablemente se implementen para la mitigación y adaptación frente al cambio climático podrían tener un mayor impacto en la biodiversidad que los efectos directos del cambio climático en las plantaciones forestales.

Se requiere una mayor comprensión de los impactos de la gestión forestal en la diversidad biológica, en particular el potencial de interacciones sinérgicas entre actividades de manejo y cambio climático (Brook et al., 2008). Además, cualquier cambio en el manejo forestal que se implemente para mitigar el cambio climático previsto continuará afectando la biodiversidad durante varias décadas, donde las plantaciones se manejarán en rotaciones largas para obtener madera o carbono.

Para maximizar las oportunidades futuras de biodiversidad y proteger los valores de biodiversidad existentes en las plantaciones, los forestales deben aumentar la resiliencia y capacidad de adaptación de las plantaciones a las condiciones climáticas cambiantes. En algunas circunstancias, esto puede requerir 
nuevos tipos de rodales de plantaciones de múltiples especies o mosaicos a escala fina de rodales de una sola especie dentro del paisaje.

Liang et al. (2016) establecieron una relación entre la biodiversidad y la pérdida en productividad a partir del análisis de 777.126 parcelas permanente, que abarcan 44 países y que contienen 30 millones de árboles de 8.737 especies, representativos de la mayoría de los biomas terrestres mundiales. Los resultados revelan que la perdida continua de biodiversidad provocaría una disminución acelerada de la productividad forestal, en todo el mundo.

El mantenimiento de la productividad forestal comercial por sí solo sería más del doble de lo que costaría implementar una eficaz conservación global. Dichos autores destacan la necesidad de una reevaluación mundial de los valores de biodiversidad, las estrategias de manejo forestal y las prioridades de conservación. Además, concluyen los beneficios potenciales de la transición de monocultivos a rodales de especies mixtas en las prácticas forestales.

Finalmente, MMA (2018) establece como meta nacional al 2030 avanzar significativamente en el uso sustentable de la biodiversidad nacional, contribuyendo a la mantención de sus servicios ecosistemicos a través de varios lineamientos estratégicos, entre los que destacan el lineamiento 4 que consiste en apoyar la implementación y reconocimiento de buenas prácticas productivas y de actividades empresariales e innovaciones ecológicamente sustentables que incluyan objetivos de protección de biodiversidad, y el lineamiento 5 incorporar elementos para reducir los impactos sobre la biodiversidad y establecer criterios para la conservación de la misma en los instrumentos de fomento productivo.

\section{ESTADO ACTUAL DE LAS INICIATIVAS PARA ENFRENTAR LAS AMENAZAS A LA BIODIVERSIDAD. NIVEL DE CUMPLIMIENTO DE ACUERDOS INTERNACIONALES}

Existe una vasta literatura de los aspectos legales y técnicos de la biodiversidad respecto a los niveles de cumplimiento de compromisos y normas internacionales vinculantes con el Estado Chileno, los que se pueden encontrar en Pérez (2014), Hermosilla (2014), Soto (2014) y Meléndez (2016), entre otros.

Dado que el Ministerio de Medio Ambiente (MMA) de Chile es el responsable de los aspectos de biodiversidad y aunque este tema en la actualidad se encuentra muy disperso en el aparato burocrático chileno, se revisará principalmente la información oficial de este Ministerio, encontrada principalmente en MMA (2019).

De acuerdo a la CEPAL ${ }^{38}$ la Convención de Diversidad Biológica (CDB) impulsó el compromiso que los países actualizaran sus respectivas estrategias nacionales de biodiversidad y sus planes de acción para la COP 13 desarrollada en Cancún, México, en diciembre de 2016. La CEPAL acordó con el MMA de Chile apoyar el proceso de creación y desarrollo de indicadores de seguimiento de la Estrategia Nacional de Biodiversidad 2017-2030.

De la misma forma, una de las primeras acciones públicas del acuerdo entre la CEPAL y el MMA de Chile, en el año 2017 fue construir y sostener indicadores de biodiversidad para el Objetivo de Desarrollo Sostenible (ODS).

La inversión en biodiversidad y ecosistemas a través de las acciones propuestas en las Estrategias Nacionales de Biodiversidad también asegura que nadie quede atrás en la implementación de los Objetivo de Desarrollo Sostenible ${ }^{39}$ (ODS) (Figura 5).

\footnotetext{
${ }^{38} \mathrm{https}$ ://www.cepal.org/es/notas/construccion-sostenimiento-indicadores-biodiversidad

${ }^{39} \mathrm{http}: / /$ www.chileagenda2030.gob.cl/
} 


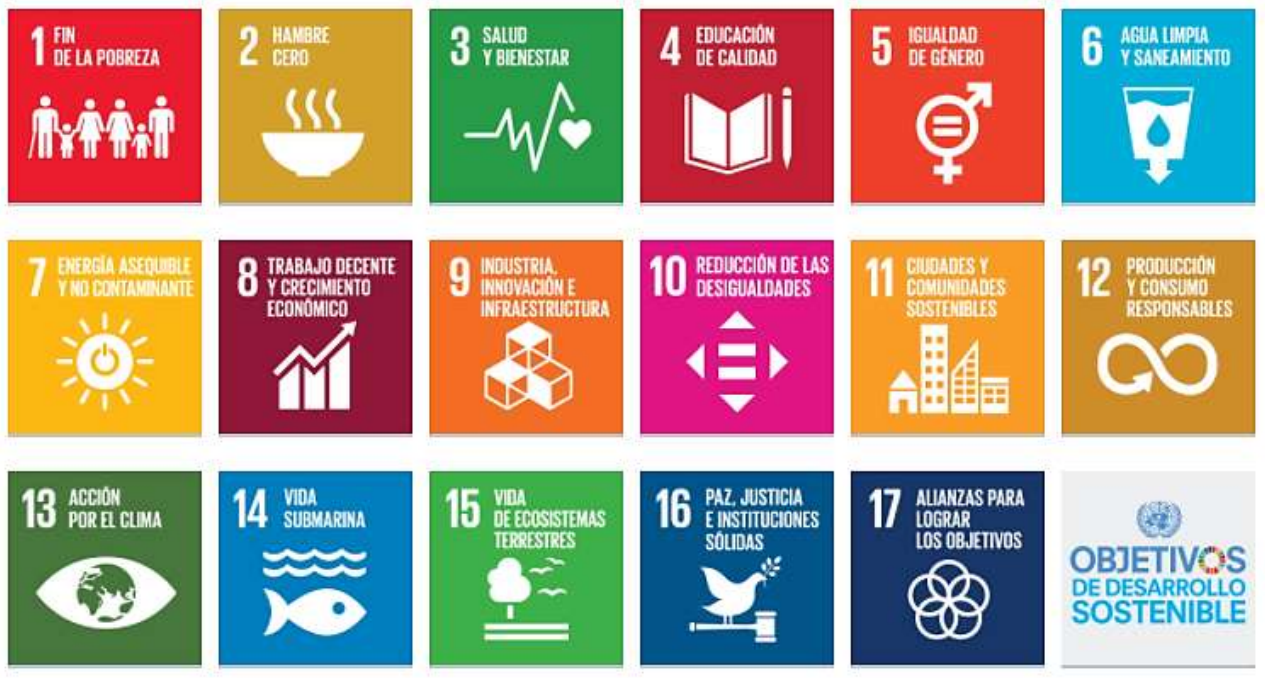

Figura 5. Objetivos de Desarrollo Sostenible (ODS)

Alonso et al. (2019) establecen que en la agenda 2030 de ODS, además de los objetivos que moldearán el diseño social y económico de los próximos años, también se encuentran objetivos para proteger el medio ambiente y la biodiversidad, de la cual depende una parte importante de la economía mundial. En específico, el Objetivo 15 promueve la Vida de los Ecosistemas Terrestres (ONU, 2018).

No obstante, el compromiso de que los países actualizaran sus respectivas estrategias nacionales de biodiversidad y sus planes de acción ha impulsado a los países a replantearse metas que permitan reorientar sus programas y políticas públicas hacia el cumplimiento de los acuerdos tomados en Japón (Metas Aichi 2020) ${ }^{40}$, y en general los países no han desarrollado indicadores de seguimiento de sus estrategias o políticas específicas de biodiversidad.

Las metas de Aichi sobre la diversidad biológica son resumidamente las siguientes:

1. Difusión de los valores de la biodiversidad.

2. Integración de estos valores y de las estrategias nacionales a la planificación.

3. Eliminación o reforma de incentivos perjudiciales y aplicación de incentivos positivos.

4. Aplicación por parte de gobiernos, empresas y grupos de interés de planes de producción y consumo sostenibles.

5. Reducción de pérdidas de hábitats y de la degradación y fragmentación.

6. Gestión sostenible de hábitats acuáticos.

7. Gestión sostenible en la agricultura, silvicultura y acuicultura.

8. Control de contaminantes.

9. Clasificación y control de especies exóticas invasoras.

10. Reducción de presiones antrópicas sobre ecosistemas acuáticos vulnerables.

11. Gestión eficaz y equitativa de aguas continentales y marinas.

12. Prevención de la extinción de especies amenazadas.

13. Mantención de la diversidad genética de las plantas cultivadas y de los animales silvestres y domésticos.

14. Restauración y salvaguarda de los ecosistemas que proporcionan servicios esenciales, incluidos aquellos relacionados con el agua.

15. Mejoramiento de la resiliencia de los ecosistemas y la contribución de la biodiversidad a las reservas de carbono.

16. Respeto al Protocolo de Nagoya sobre acceso a los recursos genéticos y la distribución justa y equitativa de los beneficios de su uso.

17. Las partes elaborarán y adoptarán estrategias y planes de acción nacionales participativos, eficaces y actualizados, en materia de diversidad biológica.

18. Se respetarán los conocimientos, las prácticas tradicionales y las innovaciones de las comunidades indígenas y las locales.

19. Se mejorarán, compartirán, transferirán y aplicarán los conocimientos, la base científica y las tecnologías relacionadas con la diversidad biológica.

20. Los recursos financieros para la aplicación efectiva del Plan Estratégico para la Diversidad Biológica de todas las fuentes deberían aumentar sustancialmente.

${ }^{40}$ http://www.ecomilenio.es/que-son-los-objetivos-aichi-para-la-biodiversidad/4490 
La Secretaria del Convenio sobre la Diversidad Biológica (2014), respecto del avance hacia la meta 3, Aichi 2020, eliminar gradualmente los incentivos perjudiciales para la biodiversidad, y 5, disminuir al menos a la mitad la tasa de perdida de todos los hábitats naturales, indica que en lo relativo a los subsidios no hay mayor avance, sin embargo, en materia de subsidios positivos si los hay, pero estos son limitados y deben orientarse a objetivos específicos. En lo referente a las pérdidas de hábitats, concluye que se continúan fragmentado y degradando hábitats de todo tipo, incluidos bosques, praderas, humedales y cuencas fluviales.

Considerando las metas de Aichi y los ODS, MMA (2019) realiza una evaluación del progreso en el desarrollo de las Metas Nacionales sobre diversidad biológica 2017-2030. A continuación, se analizan brevemente los avances de estas Metas, las que deberían estar implementadas en Chile, en el año 2030.

- Meta Nacional 1: Al 2030 se habrá avanzado significativamente en el uso sustentable de la biodiversidad nacional. Existe un progreso hacia esta mesa, pero a un ritmo insuficiente. Se ha contribuido a las metas de Aichi: 3, 4, 6, 7, 8, 14 y 15; y también a los objetivos ODS: 2, 6, 8, 9, $12,13,14,15$ y 17.

- Meta Nacional 2: Establece que al 2030 el 60\% de la población nacional estará consciente del valor de la biodiversidad nacional y los problemas ecológicos y ambientales que genera su pérdida, y el deterioro de sus servicios ecosistémicos para los sistemas naturales, para la calidad de vida de las personas y para el desarrollo sustentable del país. No se registran cambios significativos hacia esta meta. Se ha contribuido a las siguientes metas de Aichi: 1, 18 y 19; y también a los siguientes objetivos ODS: 4, 12, 14, 16 y 17.

- Meta Nacional 3: Establece que al 2030 Chile habrá avanzado en el logro de una institucionalidad que permita la conservación y gestión sustentable de la biodiversidad del país, y el $100 \%$ de las instituciones públicas con competencia directa en gestión de los recursos naturales, tanto de nivel local, regional como nacional, habrán avanzado hacia el establecimiento de un marco institucional de buena gobernanza, amplio, eficaz y coherente, y con recursos humanos, técnicos y económicos adecuados para contribuir efectivamente a conservar la biodiversidad y sus servicios ecosistémicos, y promoviendo el acceso justo y equitativo de diversos grupos de la sociedad a los beneficios que ello genere. Hay progreso hacia la meta, pero a un ritmo insuficiente. Se ha contribuido a las siguientes metas de Aichi: 16, 17, 18 y 20, y también a los siguientes objetivos ODS: 6, 14, 15, 16, 17.

- Meta Nacional 4: Propone que al 2030 las instituciones públicas, sectores productivos y de servicios del país, que generen impactos sobre la biodiversidad, habrán avanzado en la aplicación permanente de políticas y medidas para conservar y usar sustentablemente la biodiversidad nacional y sus servicios ecosistémicos. No hay cambios significativos hacia esta meta. Se ha contribuido a la meta de Aichi: 2 , y también a los siguientes objetivos ODS: 11, 12, $13,15,17$.

- Meta Nacional 5: Se supone que al 2030 se habrá reducido la tasa de pérdida de ecosistemas y especies en un $75 \%$ y será cercano a cero donde sea priorizado. Hay progreso hacia la meta, pero a un ritmo insuficiente. Se ha contribuido a las siguientes metas de Aichi: 5, 9, 10, 11, 12, 13, 14, 15; y también a los siguientes objetivos ODS: 2, 6, 14, 15, 17.

Diferentes tratados y acuerdos internacionales han sido suscritos, diversos instrumentos de política y fomento han sido establecidos y una serie acciones e iniciativas han sido tomadas, que de uno u otro modo se orientan a avanzar en el cumplimiento de las metas nacionales:

- Se ha elaborado un Protocolo de Plantaciones Forestales.

- Sector privado ha accedido a la certificación de Manejo Forestal Sustentable.

- Tratado Internacional sobre los Recursos Fito Genéticos para la Alimentación y la Agricultura (TIRFAA) 2016, y Política de Acceso a Recursos Genéticos INIA 2015.

Convención de las Naciones Unidas de Lucha contra la Desertificación (CNULD).

Estrategia Nacional de Cambio Climático y Recursos Vegetacionales (ENCCRV)

Programa de Acción Nacional de Lucha contra la Desertificación, Degradación de Tierras y la Sequía para el periodo 2016-2030. 
- Contribución Nacional Determinada Forestal de Chile (INDC, sigla en inglés), que se encuentra también alineada con el enfoque del REDD+ de la Convención Marco de las Naciones Unidas sobre el Cambio Climático (CMNUCC).

- Conciencia de la población nacional sobre la biodiversidad. Encuesta anual de satisfacción realizada en las Áreas Protegidas del SNASPE. CONAF.

- Fomento a la Investigación del Bosque Nativo. CONAF

- Creación del Sistema Integrado de Monitoreo de Ecosistema Forestales (SIMEF). INFOR, CONAF, CIREN, FAO.

- Sistema Nacional de Información Ambiental (SINIA)

Inventario de Especies Silvestres y de Humedales.

Nodo Nacional de Información sobre Biodiversidad GBIF Chile

Registro Nacional de Áreas Protegidas

Red de Monitoreo de la Biodiversidad.

Mecanismos de participación ciudadana (54), 47 relacionados con la conservación de la biodiversidad. CONAF.

- Política Nacional de Desarrollo Rural 2014-2024. Enfoque Ecosistémico. MINAGRI.

Plan Nacional de Adaptación al Cambio Climático de 2014. MMA.

Levantamiento de 109 indicadores, de los cuales, 18 se relacionan con biodiversidad.

Comité Nacional de Restauración Ecológica (CNRE). Trabaja para enfrentar 824 mil hectáreas degradadas en el país definidas por MMA.

Se estima que, pese a los esfuerzos, las tasas de pérdida de biodiversidad no han podido ser revertidas a nivel global y Chile no es una excepción. Ante esto, la inclusión de la protección de la biodiversidad en los ODS, así como el creciente número de herramientas legales y técnicas que se está desarrollando, pretenden fortalecer los esfuerzos para la protección de la biodiversidad y revertir la tendencia.

Entre las herramientas de gestión de la biodiversidad que permiten armonizar el desarrollo económico con la protección de la biodiversidad están las compensaciones en biodiversidad, que son medidas de conservación con mejoras medibles en el estado de la biodiversidad, que buscan neutralizar un impacto adverso inevitable. Estas medidas solo son aplicables a proyectos que hayan seguido rigurosamente una jerarquía de mitigación, usando las compensaciones como último recurso (IUCN, 2016).

Aún queda mucho camino por recorrer en el ámbito de la conservación de la biodiversidad genética. En efecto, el acceso a la riqueza genética nativa del país no está suficientemente regulado y tampoco existen suficientes salvaguardas. En este contexto se tiene pendiente la Meta de Aichi $\mathrm{N}^{\circ} 16$, sobre el protocolo de Nagoya, que fue adoptado el 29 de octubre de 2010 en Nagoya, Japón, y entró en vigor el 12 de octubre de 2014. Su objetivo es la distribución justa y equitativa de los beneficios derivados de la utilización de los recursos genéticos, contribuyendo así a la conservación y el uso sostenible de la diversidad biológica. Chile tiene esta deuda pendiente, ya que no ha ratificado dicho protocolo. El Protocolo de Nagoya creará una mayor seguridad jurídica y transparencia, tanto para los proveedores como para los usuarios de los recursos genéticos a través de:

- Establecer condiciones más predecibles para el acceso a los recursos genéticos.

- Ayudar a garantizar la distribución de beneficios cuando los recursos genéticos abandonan el país que los proporciona.

- Ayudar a garantizar la participación en los beneficios, el Protocolo de Nagoya crea incentivos para conservar y utilizar de manera sostenible los recursos genéticos y, por lo tanto, mejora la contribución de la diversidad biológica al desarrollo y el bienestar humano.

\section{CONCLUSIONES}

Es ya ampliamente aceptada la importancia de la biodiversidad y su estrecha relación con el manejo sostenible de los recursos naturales en todos los ámbitos de estos. La biodiversidad en un sentido amplio es la suma de la diversidad genética dentro de las poblaciones de cada especie, la diversidad de especies y la diversidad de ecosistemas, con todas sus interacciones. Esta gran diversidad es la que 
favorece la adaptabilidad y la resiliencia de especies y ecosistemas ante los cambios ambientales, y su permanencia en el tiempo.

Existen numerosos tratados internacionales relacionados con la conservación del patrimonio natural, a los cuales han adherido muchos países, a través de los cuales se han establecido objetivos y metas globales para detener la pérdida de biodiversidad. Los principales de estos son la Convención para la Protección de la Flora y Fauna Washington (1940), el Convenio sobre Zonas Húmedas-RAMSAR (1971), la Convención sobre el Comercio Internacional de Especies Amenazadas de Fauna y Flora SilvestreCITES (1973) y el Convenio sobre la Diversidad Biológica-CDB (1992), entre otros.

Los bosques cubren casi la tercera parte de la superficie terrestre y albergan a más del $80 \%$ de la biodiversidad de esta, en el caso de Chile estos cubren algo más de un quinto de su superficie. La cubierta forestal mundial está sometida a múltiples amenazas, dadas principalmente por el avance de las fronteras agrícolas, la sobreutilización y los incendios forestales, de acuerdo al FRA 2020 de FAO (2020) las pérdidas netas de bosques en el mundo se han reducido a la mitad en las últimas décadas, no obstante en el período 2010 - 2020 aún se pierden anualmente 4,7 millones de hectáreas, especialmente en la zonas tropicales.

Contrariamente, Chile es uno de los pocos países en el mundo cuya cubierta forestal se ha incrementado en las últimas décadas debido a la recuperación de bosques nativos en algunas zonas y a la expansión de las plantaciones forestales. Las grandes presiones sobre los bosque nativos cesaron a mitad del siglo pasado, hoy no hay deforestación, tampoco sustitución o esta es marginal afectando a matorrales nativos, se invierten anualmente cuantiosos recursos públicos y privados para la prevención y combate de incendios forestales, la reforestación es obligatoria, una gran parte de las plantaciones forestales se encuentra certificada bajo sellos nacionales e internacionales de manejo sostenible, y el manejo de los recursos forestales nativos está regulado y fomentado por la legislación forestal del país.

Chile posee una fuerte y desarrollada industria forestal que está basada casi exclusivamente en las plantaciones forestales, no obstante alrededor de la mitad de la superficie de bosques nativos (unos 7 millones de hectáreas) es considerada comercial y debe ser puesta en producción bajo el fomento y regulaciones del Estado, dados los beneficios económicos, sociales y ambientales que su manejo sostenible proporcionaría.

Las plantaciones forestales no tienen un gran efecto sobre la biodiversidad, han sido establecidas en suelos forestales desarbolados, praderas abandonadas por la ganadería y áreas de matorrales sin mayor valor, protegiendo los suelos y aguas, generando oxígeno, capturando y reteniendo grandes cantidades de carbono y morigerando localmente condiciones climáticas adversas. No obstante la silvicultura de estas plantaciones en muchos sectores deberá adecuarse en función del riesgo de incendios forestales, las limitaciones hídricas, el respeto a los cursos de agua y otras limitantes, y existen para esto múltiples variables que pueden ser readecuadas, como la densidad de plantación, la ubicación dentro de cuencas, las especies utilizadas, las combinaciones de especies, la alternancia de especies en grandes superficies, los tratamientos complementarios al suelo para favorecer infiltración, la mantención de corredores biológicos, la implementación de sistemas silvopastorales y silvoagrícolas, y muchas otras.

Respecto de la percepción de la sociedad sobre la biodiversidad en el país, encuestas realizadas por MMA (2028) reflejan que la protección de esta no parece ser un tema suficientemente comprendido por la sociedad y del cual se sienta parte la mayoría de la población, por lo que hay un gran desafío en este tema en el país, no obstante existen actualmente importantes esfuerzos para abordarlo en materia comunicacional y de difusión.

En lo que se refiere al monitoreo permanente de los recursos forestales, en el país existen dos sistemas nacionales de importancia dados por el Inventario Forestal Continuo del Instituto Forestal (INFOR), que ubica y actualiza anualmente la superficie de plantaciones y cuantifica las existencias volumétricas de los bosques nativos incorporando otras variables como la biodiversidad entre ellas, y el Catastro y Evaluación de los Recursos Vegetacionales Nativos de Chile desarrollado por la Corporación Nacional Forestal (CONAF), que actualiza periódicamente las superficies de bosques nativos. Ha esto se ha agregado más recientemente el Sistema de Monitoreo de Ecosistemas Nativos Forestales Nativos (SIMEF), liderado por INFOR y apoyado por FAO y GEF, que en alguna medida integra el trabajo de ambas instituciones e incorpora también al Centro de Información de Recursos Naturales (CIREN). Este 
sistema incluye los aspectos de ocurrencia y abundancia de especies de flora, vertebrados e invertebrados en bosques nativos y formaciones xerofíticas del país.

El Sistema Nacional de Áreas Protegidas del Estado abarca en la actualidad una superficie de 18,6 millones de hectáreas, administradas por COINAF, que representan casi el $25 \%$ de la superficie nacional y tienen bajo régimen de protección y conservación 3,8 millones de hectáreas de bosques nativos. A esto se suman más recientemente áreas protegidas privadas y grandes reservas marinas.

El cambio climático global con sus efectos sobre las precipitaciones y las temperaturas, y el incremento de eventos climáticos extremos, para muchos autores (Sala et al., 2000; Thomas et al., 2004; FAO, 2008) puede constituirse en una de las principales causas de pérdida de biodiversidad en todo el mundo. Dada la longevidad que poseen los árboles y los ecosistemas forestales de los que forman parte, su capacidad de adaptación es limitada para responder a cambios ambientales rápidos, por tanto son particularmente sensibles al cambio climático.

Las alteraciones que provoca el cambio climático en el bosque se refieren a variados efectos, como la abundancia relativa de especies de árboles dentro de los bosques; la fenología de estos en cuanto a estacionalidad de floración, de brotación y de fructificación; la frecuencia e intensidad de los mecanismos clave de perturbación forestal, incluidos los eventos de viento e incendios; y la dinámica poblacional de plagas y patógenos forestales.

La forestación, la reforestación y la restauración ecológica forestal son las estrategias claves para mitigar el cambio climático, por lo que es fundamental mantener en los bosques, sean plantados o nativos, suficiente variabilidad genética para adaptarse a los efectos de este cambio sobre la supervivencia de los bosques y su capacidad de proporcionar hábitat para la biodiversidad. Nuevamente destaca la creciente importancia de la silvicultura para estos efectos.

En lo que se refiere al cumplimiento de metas relacionadas con los objetivos de desarrollo sostenible nacionales e internacionales, aunque hay algunos avances, Chile y los países en general se encuentran con un nulo o bajo cumplimiento de estas.

\section{RECONOCIMIENTOS}

INFOR y los autores agradecen a la Sociedad Nacional Forestal AG, por el estímulo para concretar esta revisión y al Dr. Juan Schlatter Vollmann por sus sugerencias para mejorar el análisis.

\section{REFERENCIAS}

Alonso, V., Ayala, M. \& Chamas, P. (2019). Compensaciones por pérdida de biodiversidad y su aplicación en la minería: Los casos de la Argentina, Bolivia (Estado Plurinacional de), Chile, Colombia y el Perú, Serie Medio Ambiente y Desarrollo, № 167 (LC/TS.2019/125), Santiago, Comisión Económica para América Latina y el Caribe (CEPAL), 73 p.

Alvarez, D. \& Duran, P. (2020). Plataforma Nacional Chilena IPBES. Presentación 20 de enero 2020. Santiago de Chile. 11 p. https://mma.gob.cl/wp-content/uploads/2020/02/Plataforma-Nacional-Chilena-IPBES Daniel-Alvarez-Paz-Duran .pdf.

Barbault, R. (1997). Biodiversité. Introduction à la Biologie de la Conservation. Les Fondamentaux, Hachette, Paris.

Bertomeu, M. \& Romero, C. (2001). Managing Forest Biodiversity: A zero-one goal programming approach. Agricultural Systems, 68. Pp: 197-213. https://doi.org/10.1016/S0308-521X(01)00007-5.

Bickford, D., Posa, M.R.C., Qie, L., Campos-Arceiz, A. \& Kudavidanage, E.P. (2012). Science Communication for Biodiversity Conservation. Biol. Conserv., 151. Pp: 74-76. https://doi.org/10.1016/j.biocon.2011.12.016.

BIOFIN CHILE. (2017). PolicyBrief Biodiversidad en Chile Propuestas para Financiar su Conservación y Uso Sostenible. Resumen Ejecutivo. Hacia el Desarrollo Sostenible. Programa de las Naciones Unidas para el Desarrollo Iniciativa Finanzas para la Biodiversidad. $8 \mathrm{p}$.

Brockerhoff, E.G., Jactel, H., Parrotta, J., Quine, J., \& Sayer, J. (2008). Plantation Forests and Biodiversity: Oxymoron or opportunity?. Biodivers Conserv, 17. Pp: 925-951. https://doi.org/10.1007/s10531-008-9380-x.

Brook, B.W., Sodhi, N.S. \& Bradshaw, C.J.A. (2008). Synergies among extinction drivers under global change. Trends Ecol Evol., 23(8): 453-460. https://doi.org/10.1016/i.tree.2008.03.011.

Campos, C. (2013). Sección Especial - Percepción de la Biodiversidad. En Ecología Austral. National Scientific and Technical Research Council Buenos Aires, Buenos Aires, Argentina Diciembre 2013. Pp: 145-146. https://doi.org/10.25260/EA.13.23.3.0.1168. 
CIPMA. (2003). Manual para Guardaparques. Parte I Las Áreas Silvestres Protegidas y la Conservación de Espacios Naturales. Centro de Investigación y Planificación del Medio Ambiente CIPMA. Santiago.

CONAF. (2017). Manual para la Planificación del Manejo de las Áreas Protegidas del SNASPE. Santiago. 230 p.

CBD. (2011). COP 10 Decision X/2: Strategic Plan for Biodiversity 2011-2020. Convention on Biological Diversity http://www.cbd.int/decision/cop/?id=12268 (CBD, 2011).

Corona, P. (2016). Consolidating new paradigms in large-scale monitoring and assessment of forest ecosystems. Environmental Research, 144. Pp:8-14. https://doi.org/10.1016/j.envres.2015.10.017.

Declaración de Río Sobre Medio Ambiente y Desarrollo. (1992). Paper presentado en la Conferencia sobre Desarrollo y Medio Ambiente, Rio de Janeiro, Brasil. https://doi.org/10.18356/8d87f981-es.

Denevan, W.M. (1995). Prehistoric agricultural methods as models for sustainability. Adv. Plant. Pathol., 11. Pp: 21-43. https://doi.org/10.1016/S0736-4539(06)80004-8

De la Maza, C.L. \& Rodríguez, M. (2010). Desarrollo de un modelo de gestión sustentable en el Sistema Nacional de Áreas Silvestres Protegidas del Estado (SNASPE) para el fortalecimiento de la oferta de turismo de intereses especiales. Informe de Proyecto. CORFO, Santiago.

Diario Oficial de Chile. (1984). Ley 18.362. Crea Sistema Nacional de Áreas Silvestres Protegidas del Estado. Ministerio de Agricultura. Promulgada: 8 de noviembre de 1984. Publicada: 27 de diciembre de 1984.

Dıaz, S., Demissew, S., Carabias, J., Joly, C., Lonsdale, M., Ash, N. et al. (2015). The IPBES Conceptual Framework — connecting nature and people. Current Opinion in Environmental Sustainability, 14. Pp: 1-16.

FAO. (2008). Biodiversidad agrícola en la FAO. 46 p. http://www.fao.org/3/i0112s/i0112s.pdf.

FAO. (2010). Global Forest Resources Assessment FRA 2010 - main report. FAO Forestry. Rome, Paper. 163 p.

FAO. (2012). Forest management and climate change: a literature review. Forests and climate change working paper 10. Food and Agriculture Organization of the United Nations, Rome. En: http://www.fao.org/docrep/015/md012e/md012e00.pdf. Consulta: 28 July, 2012.

FAO. (2015). Términos y definiciones. Documento de Trabajo de la Evaluación de los Recursos Forestales No. 180. Organización de las Naciones Unidas para la Alimentación y la Agricultura. Roma, 2012. 37 p.

FAO. (2020). Evaluación de los Recursos Forestales Mundiales FRA 2020 - Principales resultados. Roma. https://doi.org/10.4060/ca8753es.

Filloy, J., Zurita, G.A., Corbelli, J.M. \& Bellocq, M.I. (2010). On the similarity among bird communities: Testing the influence of distance and land use. Acta Oecologica, 36(3): 333-338. https://doi.org/10.1016/j.actao.2010.02.007.

Fischer, M., Bossdorf, O., Gockel, S., Hänsel, F., Hemp, A., Hessenmöller, D. et al. (2010). Implementing large-scale and long-term functional biodiversity research: The Biodiversity Exploratories. Basic and Applied Ecology, 11. Pp: 473-485. https://doi.org/10.1016/i.baae.2010.07.009.

Franklin, J.F. (1993). Preserving Biodiversity: Species, Ecosystems or Landscapes?. Ecological Applications, 3(2): $202-205$. https://doi.org/10.2307/1941820.

Gilliam, F.S. \& Roberts, M.R. (1995). Impacts of Forest Management on Plant Diversity. Ecological Applications, 5(4): 911-912. https://doi.org/10.2307/2269342.

Hendee, J.C. \& Dawson, C.P. (2009). Wilderness Management. Stewardship and Protection of Resources and Values. The Wild Foundation and Fulcrum Publishing, Boulder, Colorado, USA. Chapter 1.

Hermosilla, R. (2014). Tratados internacionales vigentes en Chile en materia de protección a la biodiversidad y su relación con la legislación interna. Memoria para optar al grado de Licenciado en Ciencias Jurídicas Sociales. Universidad Austral de Chile. Facultad de Ciencias Jurídicas y Sociales. Escuela de Derecho. 63 p.

Horák, J. (2017). Insect ecology and veteran trees. J. Insect Conserv., 21. Pp: 1-5. https://doi.org/10.1007/s10841-017-9953-7.

Horak, J., Vodka, S., Kout, J., Halda, J.P., Bogusch, P. \& Pech, P. (2014). Biodiversity of most dead wood-dependent organisms in thermophilic temperate oak woodlands thrives on diversity of open landscape structures. Forest Ecol. Manage., 315. Pp:8085. https://doi.org/10.1016/j.foreco.2013.12.018.

Horák, J., Brestovanská, T., Mladenović, S., Kout, J., Bogusch, P., Halda, J.P. \& Zasadil, P. (2019). Green desert?: Biodiversity patterns in forest plantations. Forest Ecology and Management, $433 . \quad \mathrm{Pp}$ : 343-348. https://doi.org/10.1016/j.foreco.2018.11.019.

INFOR. (2020). Anuario Forestal 2020. Chilean Statistical Yearbook of Forestry 2020. Boletín Estadístico/Statistical Bulletin N 174. $274 \mathrm{p}$.

Knoke, T., Ammer, C., Stimm, B., \& Mosandl, R. (2008). Admixing broadleaved to coniferous tree species: a review on yield, ecological stability and economics. Eur. J. For. Res., 127(2): 89-101. https://doi.org/10.1007/s10342-007-0186-2.

Králová, K. \& Masarovicová, E. (2006). Plant for the future. En Ecological Chemistry and Engineering. S = Chemia i Inżynieria Ekologiczna, 13(11): 1179-1207. 
Krebs, Ch. J. (1978). Ecology. The Experimental Analysis of Distribution and Abundance. 2nd. Ed. Harper \& Row Publishers, NewYork.

ONU. (2018). La Agenda 2030 y los Objetivos de Desarrollo Sostenible: una oportunidad para América Latina y el Caribe (LC/G.2681-P/Rev.3), Organización de las Naciones Unidas. Santiago. 93 p.

OECD. (2012). Perspectivas ambientales de la OCDE hacia 2050, Consecuencias de la inacción, Organization for Economic Cooperation and Development. Puntos principales. $8 \mathrm{p}$

Paquette, A. \& Messier, C. (2010). The role of plantations in managing the world's forests in the Anthropocene. Front. Ecol. Environ., 8(1): 27-34. https://doi.org/10.1890/080116.

Paquette, A. \& Messier, C. (2011). The effect of biodiversity on tree productivity: from temperate to boreal forests. Glob. Ecol. Biogeogr., 20(1): 170-180. https://doi.org/10.1111/j.1466-8238.2010.00592.x.

Pauchard, A. \& Villarroel, P. (2002). Protected Areas in Chile: History, Current Status, and Challenges. Natural Areas Journal, 22. Pp: 318-330.

Pawson, S. M., Brin, A., Brockerhoff, EG., Lamb, D., Payn, TW., Paquette, A. \& Parrotta, J.A. (2013). Plantation forests, climate change and biodiversity. Biodivers Conserv., 22. Pp: 1203-1227. https://doi.org/10.1007/s10531-013-0458-8.

Pérez, C. (2014). Acuerdos Ambientales Multilaterales para la Conservación de la Biodiversidad Análisis de Cumplimiento en Chile. Tesis para optar al grado de Magíster en Gestión y Planificación Ambiental. Universidad de Chile. Facultad de Ciencias Forestales y de la Conservación de la Naturaleza Programa Interfacultades. Magíster en Gestión y Planificación Ambiental. $168 \mathrm{p}$.

Plath, M., Mody, K., Potvin, C. \& Dorn, S. (2011). Establishment of native tropical timber trees in monoculture and mixed-species plantations: small-scale effects on tree performance and insect herbivory. For. Ecol. Manag., 261(3): 741-750. https://doi.org/10.1016/j.foreco.2010.12.004.

Prado, J.A. (2015). Plantaciones Forestales. Más allá de los árboles. Colegio de Ingenieros Forestales. 172 p.

Puettmann, K. J., Coates, K. \& Messier, C. (2016). Crítica de la Silvicultura el manejo de la complejidad. Editorial: ACCI ediciones Asociación cultural y científica iberoamericana. 294 p.

Redford, K.H. \& Mansour, J.A. (1996). Traditional people and biodiversity in large tropical landscapes. America Verde Press (The Nature Conservancy), Arlington. Virginia.

Rockström, J., Steffen, W., Noone, K., Persson, A., Chapin, F.S., Lambin, E.F. et al. (2009). A safe operating space for humanity. Nature, 461. Pp: 472-475. https://doi.org/10.1038/461472a.

Rozzi, R., Armesto, J. \& Figueroa, J. (1994). Biodiversidad y conservación de los bosques nativos de Chile: una aproximación jerárquica. Bosque, 15(2): 55-64. https://doi.org/10.4206/bosque.1994.v15n2-09.

Sala, O.E., Chapin, F,S., Armesto, J.J., Berlow, E., Bloomfield, J., Dirzo, R. et al. (2000). Global biodiversity scenarios for the year 2100. Science, 287. Pp: 1770-1774. https://doi.org/10.1126/science.287.5459.1770.

Santibañez, F. \& Royo, A. (2002). Capítulo 5: Suelos. En: Instituto de Asuntos Públicos. Informe País Estado del Medio Ambiente en Chile. 2002. Universidad de Chile. Lom Ediciones. Santiago.

Santibañez, F. \& Santibañez, P. (2018). Evaluación de las forzantes bioclimáticas en la sustentabilidad de las comunidades de Araucarias en Chile. Hacia una estrategia de conservación del patrimonio natural frente a la amenaza del cambio climático. INFODEP. Santiago, Agosto de 2018.

Secretaría de la Convención sobre la Diversidad Biológica. (2014). History of the Convention on Biological Diversity. http://www.cbd.int/history/default.shtml.

Solbrig, O.T. \& Solbrig, D.J. (1994). So Shall You Reap: Farming and Crops in Human Affairs, Island Press. Better World Books. Mishawaka, IN, USA. 284 p.

Soto, L. (2014). Régimen jurídico de conservación de la biodiversidad en Chile. Tesis Doctoral. Programa de Doctorado en Derecho Ambiental. Facultad de Derecho. Universidad de Alicante, España. 685 p.

Spellerberg, I.F. (1991). Monitoring Ecological Change. Cambridge University Press, UK, 334 p.

Stephens, S.S. \& Wagner, M.R. (2007). Forest Plantations and Biodiversity: A Fresh Perspective. Journal of Forestry, 105(6): 307313.

Steffen, W., Richardson, K., Rockström, J., Cornell, S. E., Fetzer, I., Bennett, E. M. et al. (2015). Planetary boundaries: Guiding human development on a changing planet. (January 15, 2015) Science, 347 (6223).

Swift, M.J. \& Anderson, J.M. (1993). Biodiversity and ecosystem function in agricultural systems. En: Schulze, E.D. \& Mooney, H.A. (Eds). Biodiversity and ecosystem function. Springer, Berlin Heidelberg New York Berlin. Pp: 17-38.

Thomas, C.D., Cameron, A., Green, R.E., Bakkenes, M., Beaumont, L.J., Collingham, Y.C. et al. (2004). Extinction risk from climate change. Nature, 427(6970): 145-148. https://doi.org/10.1038/nature02121.

Torras, O. \& Saura, S. (2008). Effects of silvicultural treatments on forest biodiversity indicators En: the Mediterranean. Forest Ecology and Management, 255. Pp: 3322-3330. https://doi.org/10.1016/j.foreco.2008.02.013. 
Unda, A. (2016). Pautas para Identificación, Manejo y Monitoreo de Altos Valores de Conservación de FSC en Chile. FSC-CHILE. $159 \mathrm{p}$.

UICN. (2008). La conservación forestal con un enfoque de derechos. Arborvitae. Boletín del Programa de Conservación de Bosques de la UICN n.36. 16 p.

Universidad de Chile. (2016). Informe País: Estado del Medio Ambiente en Chile. Instituto de Asuntos Públicos, Centro de Análisis de Políticas Públicas. 605 p.

Uribe, A. \& Estades, C. (2010). Manejo de Plantaciones de Pinus radiata y Conservación de Fauna Silvestre. Ambiente Forestal. Revista de Extensión, 5(9): 12-19.

Vivanco Font, E. (2019). Biodiversidad global. Impacto del cambio climático en el Reporte de Biodiversidad 2019. Biblioteca del Congreso Nacional de Chile | Asesoría Técnica Parlamentaria. № SUP: 121124. 9 p.

Weber, C. \& Gutiérrez, A. (1985). Áreas Silvestres Protegidas. Capítulo 4: 139163. Medio Ambiente en Chile. Centro de Investigación y Planificación del Medio Ambiente (CIPMA). Santiago.

Wolynski, A. (2002). Notas breves sobre la evolución histórica de la silvicultura naturalística. El Boletín de Prosilva, 1. Pp: 28-35.

WWF. (2016). Planeta Vivo. Informe 2016. Riesgo y resilencia en una nueva era. WWF International Avenue du Mont-Blanc 1196 Gland, Suiza www.panda.org. 148 p.

WWF. (2018). Living Planet Report - 2018: Aiming Higher. Gland, Switzerland.

WWF. (2019). Clima, Naturaleza y un Futuro con $1,5^{\circ} \mathrm{C}$. WWF International. 40 p.

Zaninovich, S.C. (2017). Dinámica y almacenamiento del carbono en la necromasa y el suelo de ecosistemas forestales: Efecto de la degradación del bosque nativo y su reemplazo por plantaciones de Pinus taeda L. en el NE de Argentina. Tesis Doctoral. Doctor de la UNNE en Biología Universidad Nacional del Nordeste. Facultad de Ciencias Exactas y Naturales y Agrimensura. $178 \mathrm{p}$. 